\title{
How Obelisks Were Constructed, Moved, Shaped, and Erected in the Ancient Egypt
}

\author{
Akio Kato \\ 1521-461, Hiekawa, Izushi, Shizuoka Pref., Japan \\ Email: akiokato1521@gmail.com
}

How to cite this paper: Kato, A. (2021). How Obelisks Were Constructed, Moved, Shaped, and Erected in the Ancient Egypt. Archaeological Discovery, 9, 16-51. https://doi.org/10.4236/ad.2021.91002

Received: November 26, 2020

Accepted: January 17, 2021

Published: January 20, 2021

Copyright ( 2021 by author(s) and Scientific Research Publishing Inc. This work is licensed under the Creative Commons Attribution International License (CC BY 4.0).

http://creativecommons.org/licenses/by/4.0/

\begin{abstract}
An entirely new feasible theory is presented about how they constructed, moved, shaped, and erected obelisks in ancient Egypt around 1500 BC. In particular, we propose two simple ways to erect obelisks, inspired by the historical fact that all of obelisks were originally erected "in pairs," except the single "Lateran" obelisk. Our aim is to "excavate" ancient Egyptian methods to raise heavy high obelisks, using only the most primitive means including forerunners of pulley, but excluding further mechanical devices, like capstan or winch, which were employed in most cases of re-erection and re-location of obelisk outside of Egypt.
\end{abstract}

\section{Keywords}

Obelisk, Pulley, Moment

\section{Introduction}

We present a new theory of how obelisks were constructed, moved, shaped, and erected in ancient Egypt. This theory is entirely new, never appeared before in literatures, and aims at "excavating" the architectural techniques in ancient Egypt buried in the passage of time. Due to the religious or aesthetic reason obelisks were originally erected "in pairs" at the entrance of ancient Egyptian temple, except the single "Lateran" obelisk commissioned by Tuthmosis III (1504-1450 $\mathrm{BC}$ ). Though "erection of two obelisks" usually implies the doubling of efforts to erect each one, we propose in this article how to turn this disadvantage into an advantage. In other words, we assume that the ancient Egyptians found a new architectural reason that high obelisks were easier to be raised "in pairs" than to be raised separately. The prototype of our way of erection can be seen in Figure 35 where one obelisk, acting as an anchor, helps another to be raised. The ropes 
and the carrier with rotatable poles are our principal means, and our method of erection of a pair of obelisks, described in Section 5 or Section 6, is quite effective and much simpler than the methods appeared hitherto in literatures (Engelbach, 1923; Isler, 1976; Habachi, 1985). We never used any "modern" mechanical devices like capstan or winch, which were employed in most cases of re-erection and re-location of obelisk outside of Egypt. Even using such mechanical devices, re-erection and re-location was quite hard as described in many literatures (King, 1880; Gorringe, 1885; Siwicki, 2020; Brier, 2021). What we include in "ancient" mechanical devices is "forerunners of pulley" so that we assume throughout this article that:

Forerunners of simple or movable pulley were used with ropes in moving and raising stones.

This assumption we already adopted in (Kato, 2020) as a reasonable one to explain the construction of the Great Pyramid and so, we may even be able to adopt more than this, since the time of high obelisk we concern in this article is about 1500BC, a millennium after the Pyramid Age. A bit precisely, we might say that the history of the truely high obelisks started when Sesostris I (19711928 BC, the Middle Kingdom) erected obelisks, one of which is 20.7 meters high (weighs about 121 tons) and is still standing in its original position at Heliopolis; see the chronological list of obelisks in (Jansson, 2019). About "pulley" Arnold (Arnold, 2003: p. 195) notes that "stone grooves and pulleys, around which ropes would have passed, are preserved from the 4th Dynasty, and wooden wheels for simple rope pulleys existed from the Middle Kingdom onwards." As for rope, its good examples can be seen in the Great Boat of Khufu museum; Soros (Soros, 2018) praises the outstanding ability of ancient Egyptians in making rope, and noted that "pieces of ancient rope with a diameter of twelve or thirteen centimetres are found, capable of a strain of several tons." See also (Arnold, 1991: Fig. 6.25).

General Caution about Figures: Most of our figures are not in scale since obelisks are too long, and are simplified to illustrate "mechanism" rather than the actual way in which many strong ropes as well as thick poles or posts would be necessary.

This article is organized according to the timeline from the extraction to the erection of obelisk. First, we explain in Section 2 how an obelisk was cut and extracted from the bedrock. Next, in Section 3 how it was moved, and in Section 4 how it was shaped. Erection of a pair of obelisks is explained in Section 5 and Section 6 showing its force diagram to estimate moments. Section 7 proposes how to erect a single obelisk, and Section 8 explains how to set an obelisk on its pedestal. The only topic we did not concern in this article is about how the obelisk on the barge was transported down the Nile to its destination, about which see (Engelbach, 1923; Hoogeveen, 2018; Jansson, 2019). We have utilized the fine report (Negus, 2015) about the Unfinished Obelisk in Aswan, and could uncover almost all of myths questioned there. 


\section{How to Cut and Extract an Obelisk from the Bedrock}

We begin to explain how an obelisk was cut and extracted from the bedrock. A good resource to learn the way can be found in the Unfinished Obelisk in Aswan, about which (Negus, 2015) reports that:

"It was cut from the granite bedrock with the great uniformity in their cuts and shape. These cuts are quite consistent in their verticality and width in such a way that the cut lines are vertical to the horizon not to the obelisk (the obelisk itself lies on the slope of 10 degrees to the horizontal), and the sides of the cuts, each approximately 20 to $25 \mathrm{~cm}$ wide, show vertical ridge lines at a regular spacing, the face between these ridge lines in nearly flat and the ridges themselves are minimal in height. At the bottom of the cut there is a radius."

Taking account of these observations and as well the excavated examples of axe head and rammer (Arnold, 1991: Fig. 6.12, Fig. 6.17), we propose a thick blade for cutting an obelisk as illustrated in Figure 1 where the size of $P Q$ is about a foot or 30 centimeters. Such a blade should be made of stone, a bit harder than the red granite of the bedrock. But the red granite itself is quite hard, so we believe such a blade was easy to be blunt and consumed a lot. To cut an obelisk, such a blade, set in proper position, should be hit by a strong force, and the best way to generate such a strong power would be to drop a heavy stone in the way of Figure 4 and Figure 5. (Such simple mechanism can be seen nowadays in the so-called "pile driver" or "post pounder.") So, some device to raise and drop a heavy stone would be needed, and we propose a wooden lift with horizontal rotatable poles as in Figure 2, which was already proposed in (Kato, 2020) for the construction of the Great Pyramid. Figure 2 is somewhat simplified to show rather its mechanism (as remarked at the end of Section 1), and note that the vertical thick posts in this figure can be replaced by any wooden towers as in Figure 3, where two such towers support a rotatable pole. One man's pulling down force would be about $70 \mathrm{~kg}$ or $80 \mathrm{~kg}$ utilizing his weight. A cubic stone of side length half a meter weighs about $300 \mathrm{~kg}$ so that it can be raised only by four men. But, a bit unexpectedly, a cubic stone of side length 0.7 meters, weighing about $850 \mathrm{~kg}$, needs twelve $(850 / 75=11.33 \cdots)$ many men to be raised. Therefore, in Figure 2 the dimensions of the stone would be appropriate if the maximum of its side lengths is half a meter, assuming that four men pull down the ropes. Observe that the horizontal rotatable poles in Figure 2 can act as simple pulleys (see Section 9).

To cut vertically into the bedrock, we can use the simple method of Figure 4, while, to cut slantwise we need some additional control over the direction of the blade like Figure 5. It would not be easy to carve the lower side flat, so we better carve it convexly like Figure 6 employing the method of Figure 5 still utilizing the gravity, and the final whole entity extracted from the bedrock should be like Figure 7 with the convex lower side, either (1) or (2), resembling some cargo ship. Such a convex shape reinforces the whole structure. For instance, as pointed out in (Negus, 2015), suppose on the contrary that the lower side were 


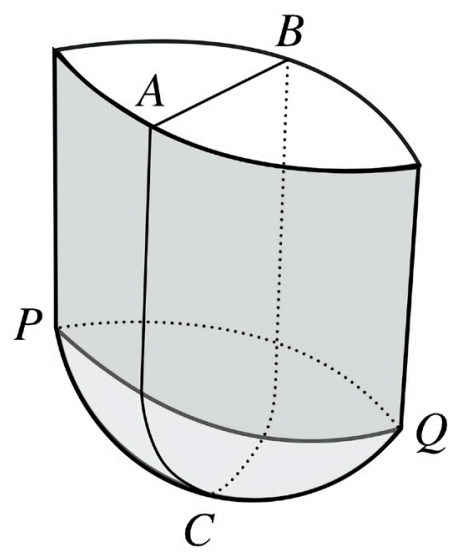

Figure 1. Blade for cutting obelisk.

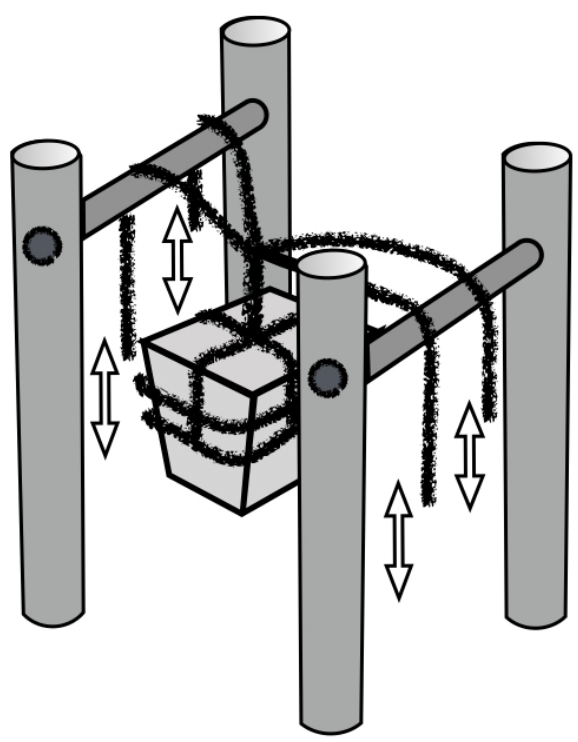

Figure 2. Wooden lift to raise and drop a stone.

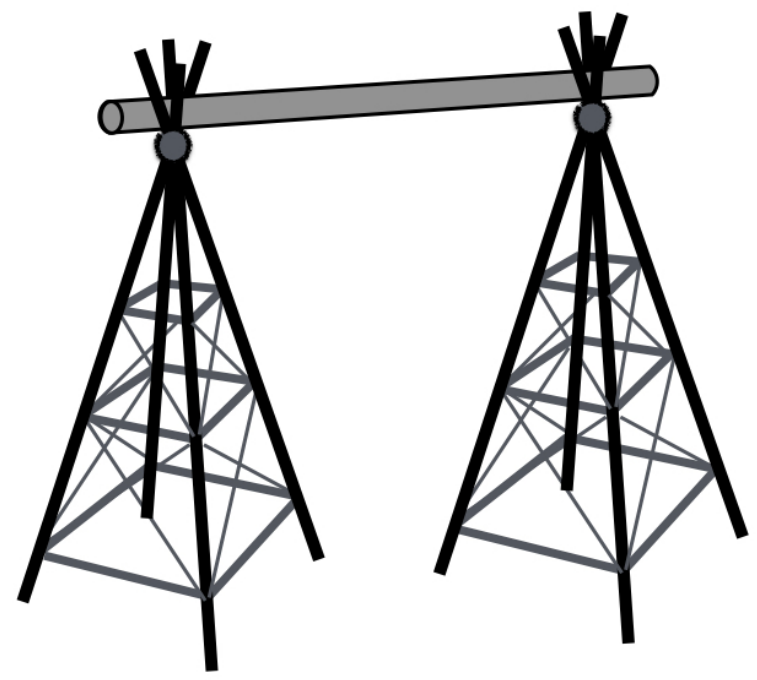

Figure 3. Two towers supporting a rotatable pole. 


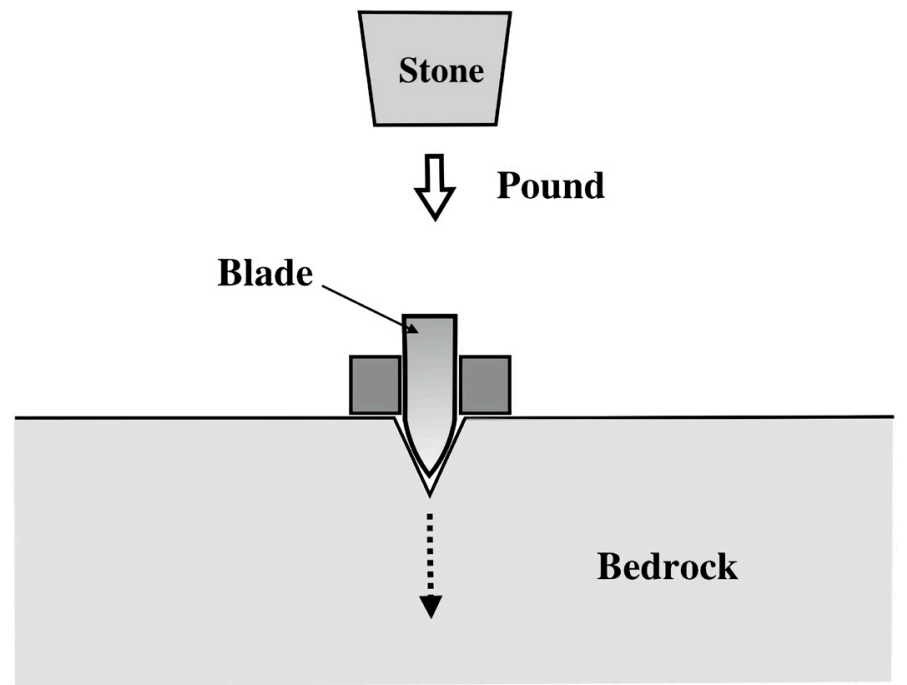

Figure 4. How to use the blade to cut vertically into the bedrock. The blade in this illustration is the cross sectin $A B C$ of Figure 1, and is kept vertical by the two stones (colored dark grey).
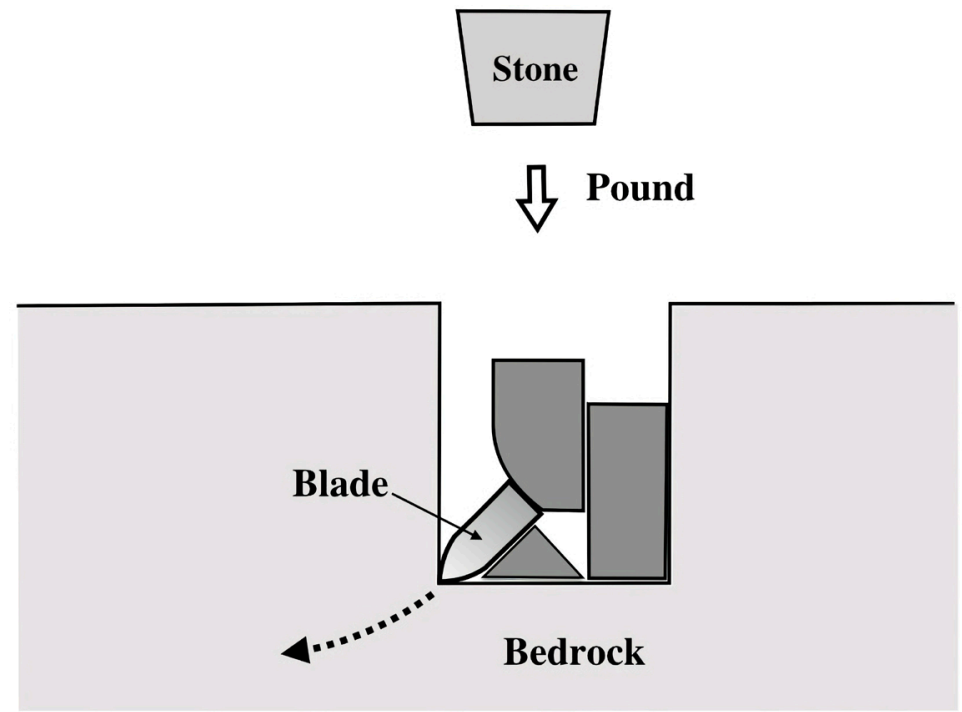

Figure 5. How to control the blade using stones (colored dark grey).

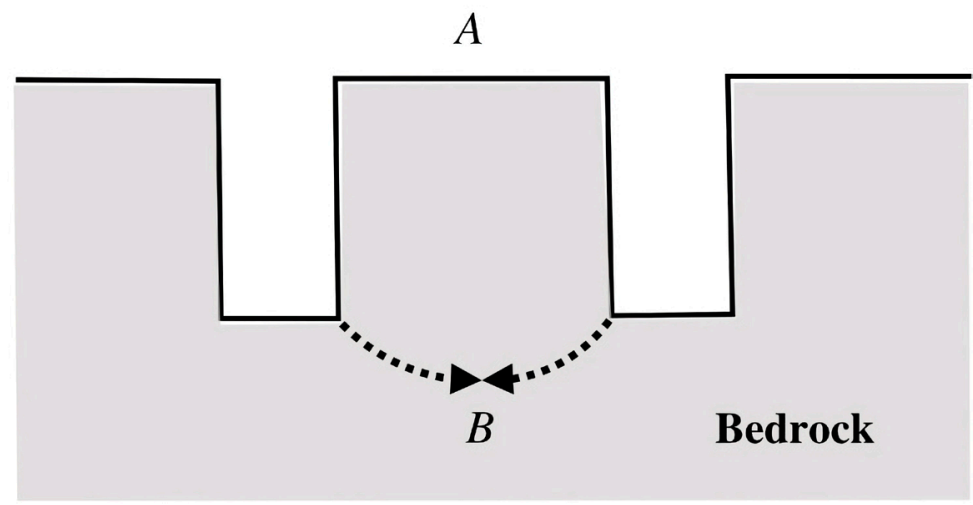

Figure 6. How to carve the lower side. 
(1)

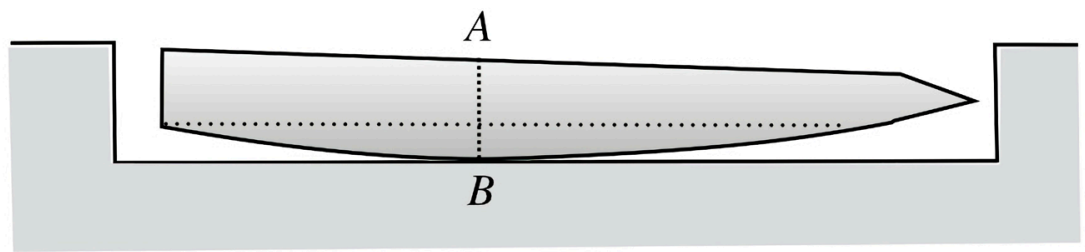

(2)

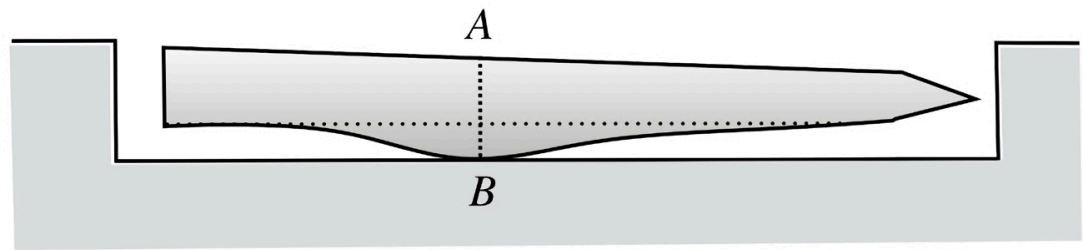

(3)

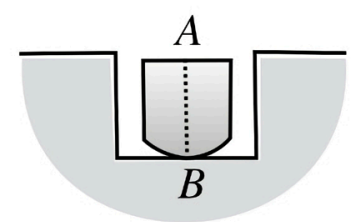

Figure 7. Vertical cross sections of the pre-obelisk to be extracted from the bedrock; (1) or (2) is along the central axis of the obelisk, and (3) is along the plane passing $A B$, parallel to the bottom face of the obelisk.

carved flat, then the long heavy obelisk would be snapped in two once the middle of the flat side were placed with a jerk on some stone. The convex shape also makes easy to maneuver the obelisk, as will be explained in the next section. Let us temporarily call such convex obelisk pre-obelisk, short for "predecessor of obelisk," and its convex lower part belly.

Now, suppose we have succeeded in detaching the belly from the bedrock so that the pre-obelisk lies in the "dock" of bedrock as illustrated in Figure 7. Then how should we raise this pre-obelisk up to the ground level? Our solution is "rolling," i.e., an oscillation around the long axis, one of the technical terms used for ship as in Figure 8. First, pass many ropes around the pre-obelisk, each one as in (1) of Figure 9. Note that we can pass ropes under the belly since the belly touches the bottom of the dock only on its small central part, thanks to the convexity, as can be seen in Figure 7. Next, pour some sand into the trenches, and "roll" the pre-obelisk by pulling each side of rope alternately as in (2). This simple rolling works due to the convexity of the belly, and would not need so big power since it is rather an oscillation, not a lift. Then, the sand will "flow" downwards to raise the pre-obelisk a bit as in (3) of Figure 10, looking like "the ship of obelisk floats on sand." The point is that "rolling" stirs sand, and moving sand behaves like water, hence it would be better to keep the sand stirring with oarlike sticks, while rolling. Repeating this process many times, each time pouring small amount of sand and rolling, we will finally be able to raise the pre-obelisk up to the ground level as in (4) of Figure 10.

Two shapes of the pre-obelisk were proposed in Figure 7: The shape (1) would 


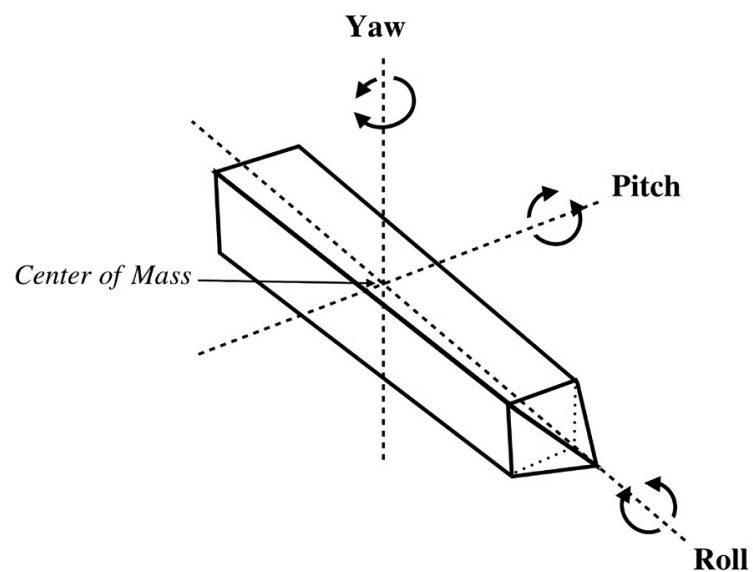

Figure 8. Terms used for ship.

(1)

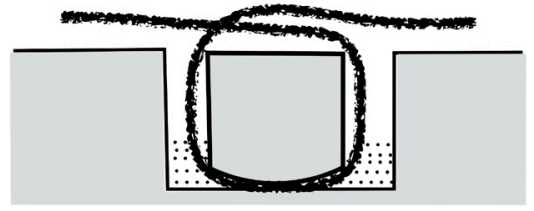

(2)

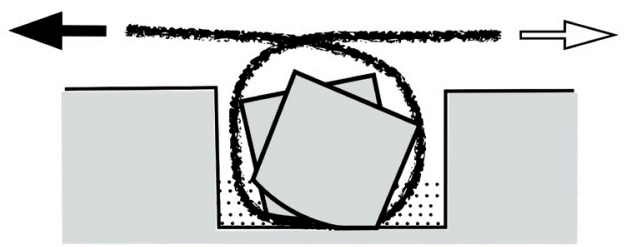

Rolling

Figure 9. Rolling to raise the pre-obelisk.

(3)

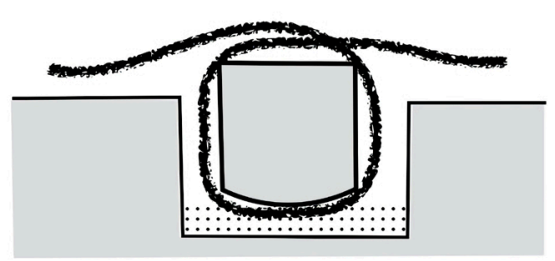

(4)

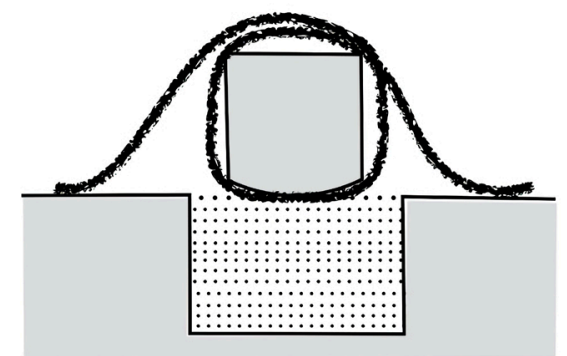

Figure 10. Raising up to the ground level. 
be easier to be carved and easier to be rolled than (2), while the shape (2) would be lighter and hence easier to be moved than (1). Thereore, the best choice is that: First carve the pre-obelisk in the shape (1) and raise it to the ground level by rolling, then shape it into the slim form (2) for moving.

\section{Summary of Section 2:}

Using a simple lift Figure 2 with a heavy stone to pound a big blade Figure 1 into the bedrock, we can cut and extract from the bedrock a "pre-obelisk," a predecessor of obelisk with a convex belly like a ship. After detaching the belly from the bedrock, we can apply "rolling," an oscillation around the long axis, to raise the pre-obelisk up to the ground level.

\section{How to Move an Obelisk Overland}

Now we need to move the extracted pre-obelisk overland. The geological details around the Unfinished Obelisk was described in (Negus, 2015) that:

"The obelisk lies on the slope of 10 degrees to the horizontal, and it would be in the order of 6 meters above the adjacent level surface and would have had to have been moved approximately 65 meters to that area (i.e., the riverside where the obelisk was to be loaded on to some barge). The course leading down to the river need not be straight."

Taking care of these observations, we now show how to move the pre-obelisk. Assume that the pre-obelisk is now on the ground level as in (4) of Figure 10. Then, first we enclose it with a wooden framework as in Figure 11 and Figure 12. Notice that the central part of the belly of the pre-obelisk remains touched upon the ground, in other words, the pre-obelisk is not "on" the framework. This framework, looking like a skeleton of a barge, is composed of round poles and would not be so difficult to be built just by inserting (relatively) short poles into the holes of thicker poles. These inserted poles may or may not be rotatable, but note that these properties can be convertible when used with ropes: Rotatable pole can be fixed whenever neccesary by inserting wedge between it and the hole, while any fixed pole can be converted into an essentially rotatable one by wearing a bronze tube on the contact surface of the pole with a rope as in Figure 13 , or by lubricating the contact surface. Such a care would be preferable, if possible, also for rotatable poles in order to protect both poles and ropes from wearing out. Thus we can assume that all round poles are essentially rotatable.

Now fasten the pre-obelisk well with the framework using ropes as in Figure 12. Then we pass ropes around poles of this framework as in Figure 14 and pull the free ends of ropes to move the pre-obelisk rightwards. Each rope on the right side of Figure 14 passes around one or two round poles which act as "movable pulleys" together with some fixed post. See Remark 3.1 for this mechanism. Though Figure 14 illustrates only a few ropes and poles, practically many many ropes, poles and posts would be necessary to move the heavy pre-obelisk. Indeed, the main reason we introduced the wooden framework is to provide many essentially rotatable poles, and the framework can be extended whenever more 


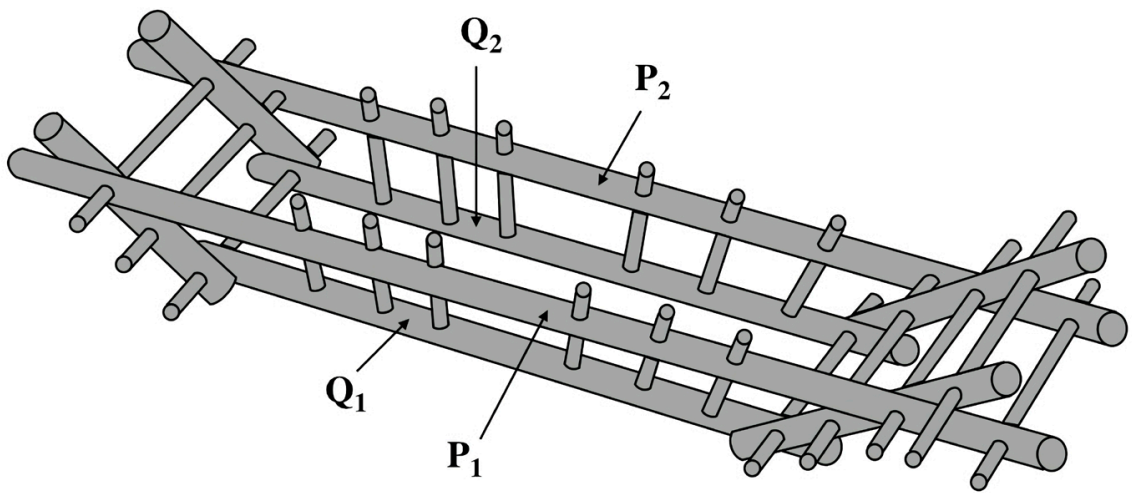

Figure 11. Wooden Framework, looking like a skeleton of a barge, for Moving the Preobelisk, with upper long poles $P_{1}, P_{2}$ and lower long poles $Q_{1}, Q_{2}$. (Not in scale: Actually, $P_{1}, P_{2}, Q_{1}, Q_{2}$ should be very long, more than 20 meters.)
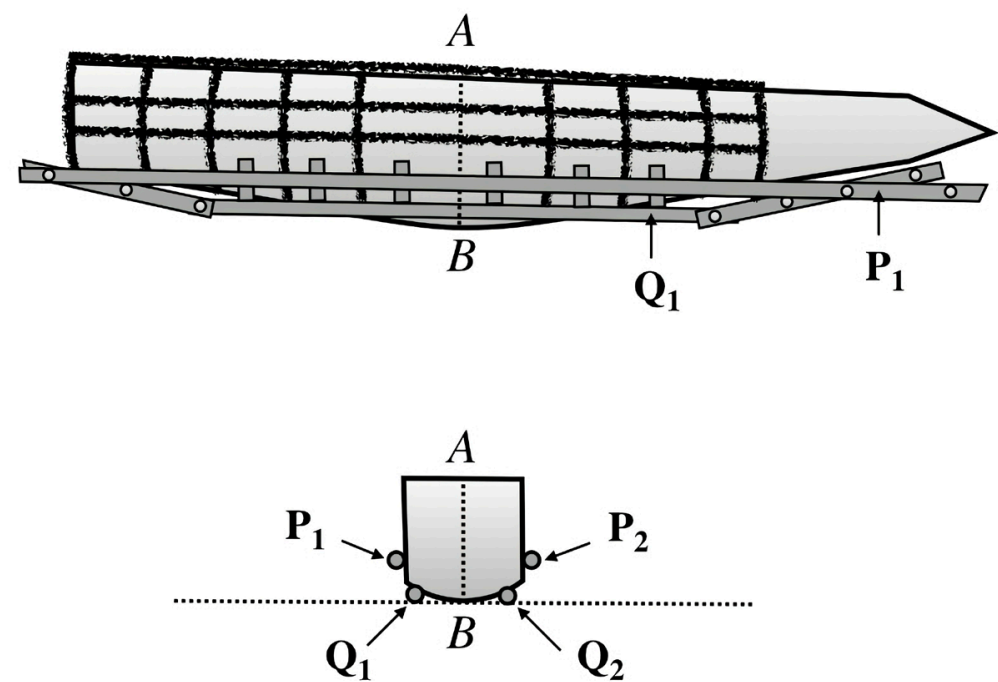

Figure 12. Pre-obelisk equipped with the framework of Figure 11. Above: side-view, below: cross-section along $A B$.

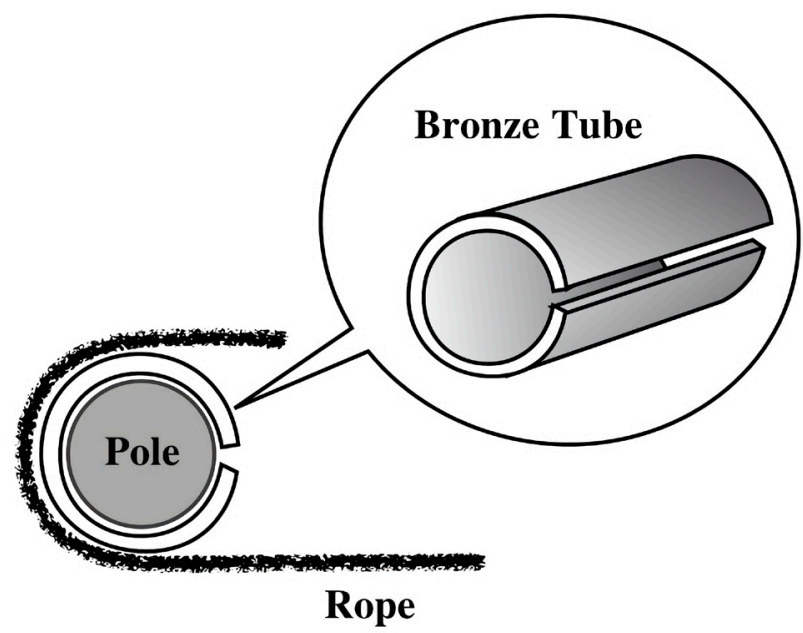

Figure 13. Wearing a Bronze tube on a pole to reduce the friction with a rope (Side view). 


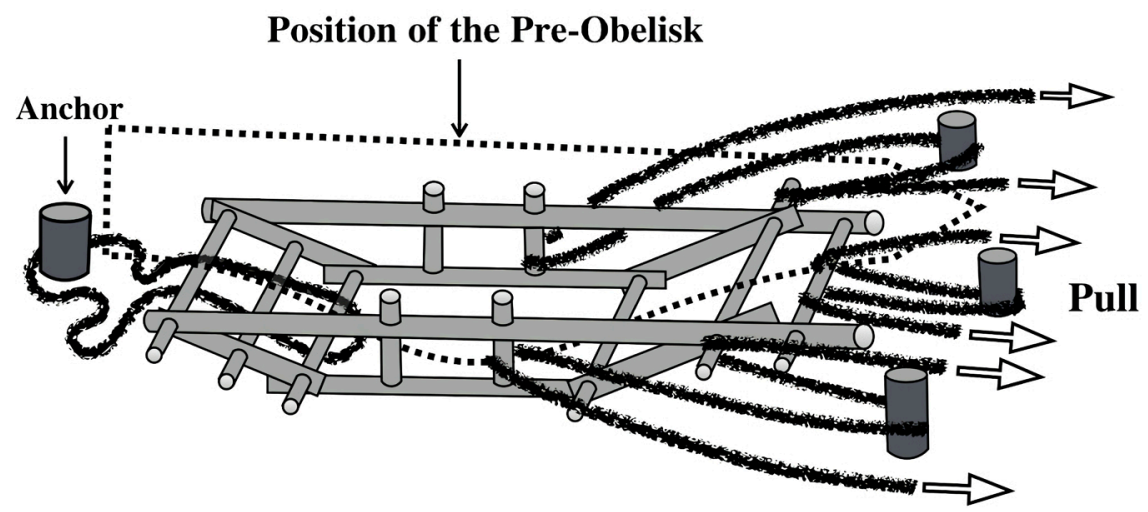

Figure 14. How to move the pre-obelisk using ropes.

poles are needed. The big post on the left side of Figure 14 is an "anchor" for the ship of pre-obelisk, and many of such anchor would be needed in the might-bedangerous move on a downhill. The fact that the convex belly touches the ground only on its small central part has various advantages in moving the pre-obelisk. For example, it will be not so difficult to turn the pre-obelisk around the center of the convex belley, like "yaw" (see Figure 8), since the pre-obelisk is long enough for a force couple to be applied efficiently. By the same reason "pitching" the pre-obelisk would be also possible and helpful in moving over some bumps. Surely some abrasion would occur to the belly, but this causes no problem since the convex belly would be removed to be leveled at the destination of obelisk. It would be also possible to place wooden rollers just before the central part of the belly, and the length of these rollers should be a bit shorter than the distance of the two long poles $Q_{1}$ and $Q_{2}$ (see Figure 12), so they need not be long.

As is well known, long thick woods were scarce in ancient Egypt (Jansson, 2019), but they were quite needed as the case of the wooden framework of Figure 11. So, we believe the ancient Egyptians would have some ideas to get around such difficulties, perhaps like Figure 15 or Figure 16. Long poles like

$P_{1}, P_{2}, Q_{1}, Q_{2}$ in Figure 11 can be obtained by connecting short ones as in Figure 15 using ropes (or the bronze tube of Figure 13 instead of ropes). Thick pole with holes big enough to accept strong rotatable poles are also needed, and such one could be obtained by combining two poles as in Figure 16; we can see such an example in Figure 17.

The report (State, 2007) revealed that "The unfinished Obelisk Quarry in Aswan, Egypt, has a canal that may have connected to the Nile and allowed the large stone monuments to float to their permanent locations." So, the pre-obelisk might be moved by such a canal, not overland, from the quarry to the Nile. Note that even in canal we can still apply our moving method of Figure 14, fixing the posts on the banks of the canal. The ship-like shape of the pre-obelisk in Figure 7 as well as the barge-like wooden framework of Figure 11, getting some buoyancy, would be quite appropriate also in canal. Imagine the pre-obelisk of Figure 12 in the canal, which would surely look like a cargo ship! 


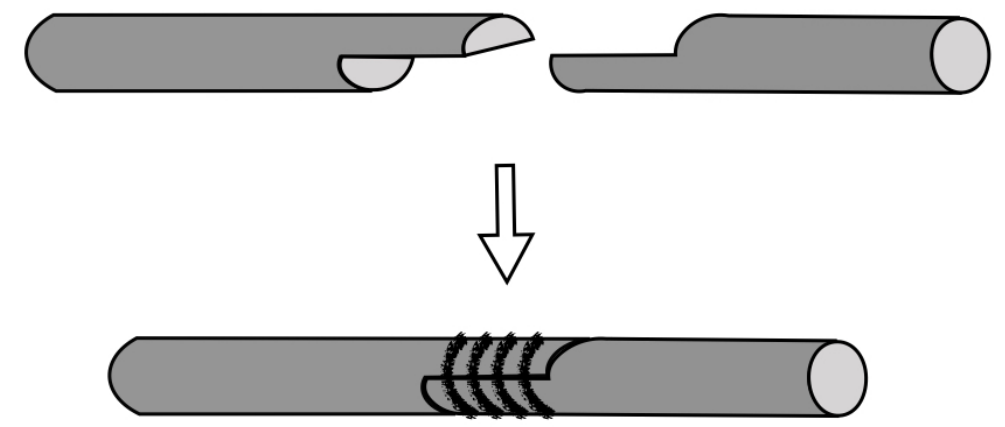

Figure 15. Connecting short poles to get a long pole.

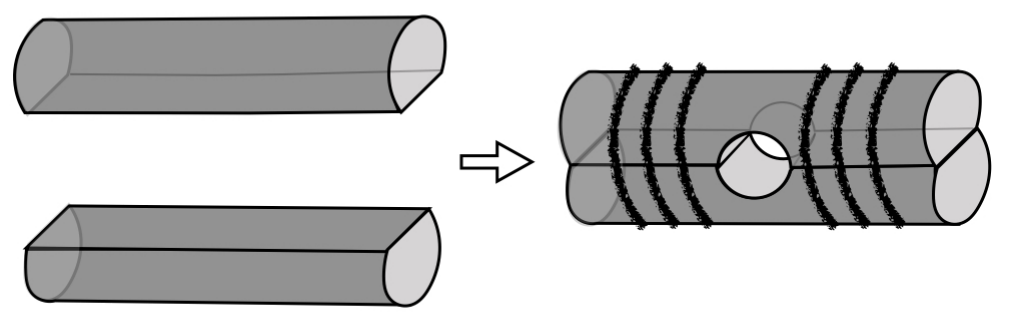

Figure 16. Combining two poles to get a pole thick enough to have a big hole.

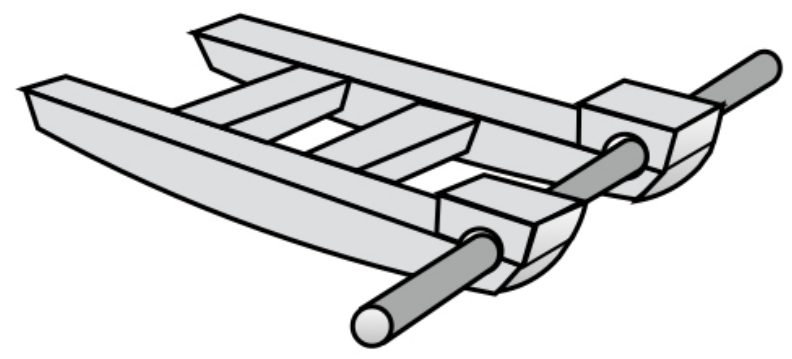

Figure 17. Sledge with a rotatable round pole at its front.

\section{Summary of Section 3:}

The "ship" of pre-obelisk can be moved overland by enclosing it with a wooden framework like a skeleton of "barge." We can pass many ropes around the poles of the framework, and pull them to move the pre-obelisk utilizing essentially the mechanism of "movable pulley" as described in the next Remark 3.1. Note that the belly of the pre-obelisk remains touched upon the ground.

Remark 3.1. Let us explain the mechanism of Figure 14. Consider a sledge of Figure 17 with a round pole at its front, and let us regard this sledge as a simplified version of the framework of Figure 11. Suppose we want to move a stone using this sledge, and pass ropes around the front pole as in Figure 18 where only two ropes are shown for simplicity. Assume the both ends of each rope are pulled by the forces $F_{1}, F_{1}^{\prime}$ and $F_{2}, F_{2}^{\prime}$ such that $F_{1}=F_{1}^{\prime}=F_{2}=F_{2}^{\prime}$ approximately. Then the stone will move if the sum of these forces $F_{1}+F_{1}^{\prime}+F_{2}+F_{2}^{\prime}$ overcomes the friction force between the sledge and the ground. But this simple way would need many men to pull ropes, and with use, we believe, they soon found its improved version Figure 19 to reduce the number of needed men, 


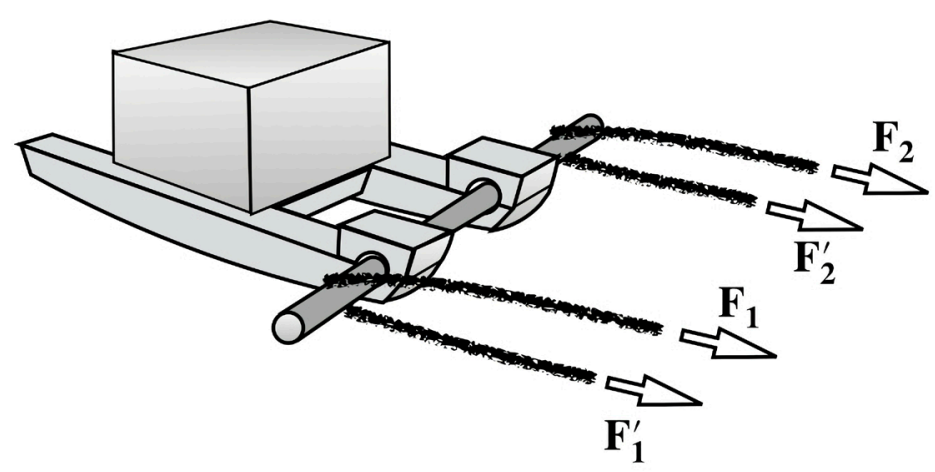

Figure 18. Use of a sledge and ropes to move a stone.

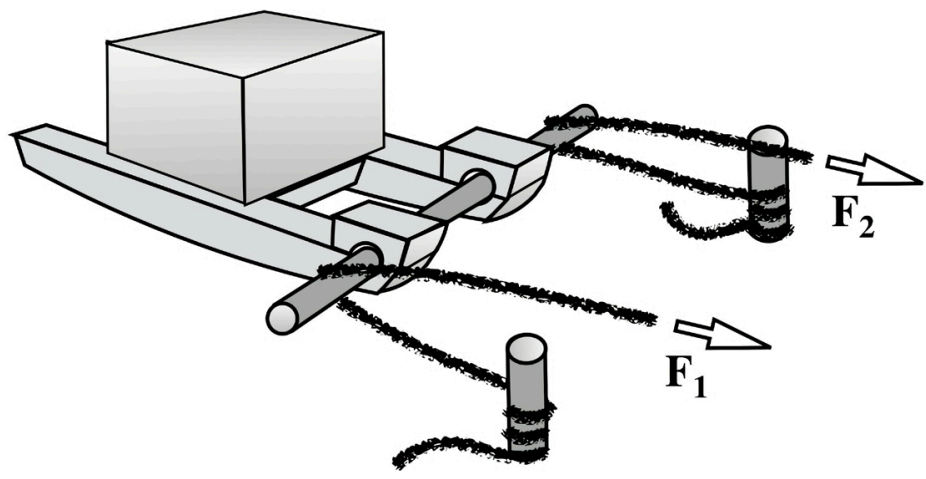

Figure 19. Use of anchoring posts to reduce the pulling power by half compared with Figure 18.

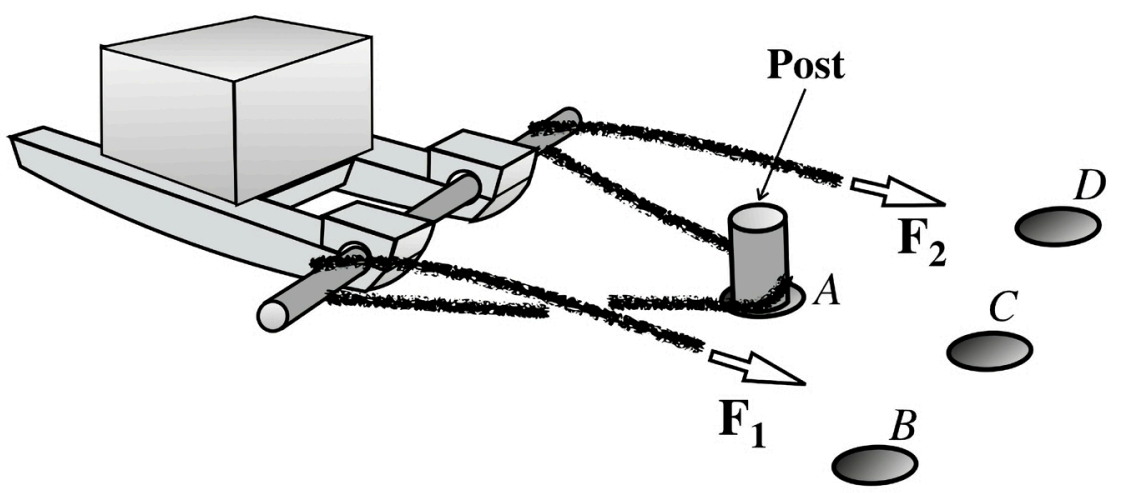

Figure 20. Effective use of post improving the case of Figure 19. $A, B, C, D$ are holes for posts.

perhaps through the following experience. For example, suppose the men applying the forces $F_{1}^{\prime}, F_{2}^{\prime}$ were lazy in pulling, and the ropes were pulled mainly only by the men applying the forces $F_{1}, F_{2}$. Then, the ropes sliding around the round pole would have still moved the stone, though a bit slowly. Consequently they would have learned that the stone can be moved even if one end of each rope is anchored to something fixed like Figure 19, and that the front pole is better to be rotatable. Such a front pole acts as a "movable pulley" and reduces almost by half the effort needed to move the stone, while increasing twice the 
distance to pull (see Section 9). We can further improve Figure 19 into Figure 20 which decreases the number of fixed posts just by hanging a rope on a fixed post as was the case of Figure 14. In order to use such a post effectively we better prepare many deep holes like $A, B, C, D$. Then, for example, when we want to move the stone in the direction $\overrightarrow{A C}$, we can first move the post from the hole A into the hole $\mathrm{C}$, and then pull the rope. We believe that this kind of simple sledge like Figure 17 was already utilized in the construction of the Great Pyramid around $2500 \mathrm{BC}$, a millennium earlier than the age of high obelisk.

\section{What to Do before Erection of Obelisk}

As mentioned in Section 1, we do not argue about how the obelisk on the barge was transported down the Nile to its destination. So, now assume that the pre-obelisk arrived at the site of its erection. Then, first we need to level the belly, then a precision shaping and the inscriptions, about which we explain in detail in this section. For such purposes we need to rotate the heavy obelisk around its axis. But how should we do it? Our solution is already given essentially in (Kato, 2020), which we are going to explain. First, we prepare prisms of stone as in Figure 21, either of which can be obtained by chamfering a stone of cuboid or triangular prism, and with use any prism on the left side will soon be worn into the shape on the right side. Let us call such a stone of prism rocker. The use of such "rocker" was already introduced in (Kato, 2020: Remark 4.2) where we described it as "trapezoidal prism." (So, "rocker" in this article always means such a device made of "stone," not a wooden one as excavated.) Such rockers of suitable size would make easy to rotate the (pre-)obelisk if they were properly placed as in Figure 22. How to rotate the pre-obelisk to remove its belly, and how to rotate the obelisk for inscriptions are shown in Figure 23 and Figure 24, respectively. Though in these figures big rockers are drawn for the simplicity of illustration, they can be always replaced by a multiple of smaller rockers.

"How the precision shaping of the obelisk was done" was questioned in (Negus, 2015). We present here our answer. A simple useful device to check the flatness of a surface is a plumb, a plumb-line with a plumb-bob, which can examine if the surface is vertical or not. So, we can use it as in Figure 25 to examine the flatness of the bottom or side faces of the obelisk. Further, a pendant-like plumb or a long string of stone beads can be used for checking the vertical flatness of a two-dimensional surface, together with a straight rod, as illustrated in Figure 25. Note also that a plumb can be used to measure the height so that it is possible to draw a horizontal line on every side face of the obelisk if we use just one plumb keeping its plumb-bob barely touched to a horizontal platform set beforehand, like the line $\ell$ in Figure 25. Of course, we can draw a vertical line on every side face of the obelisk along a plumb-line. Hence we can draw both horizontal lines and vertical lines anywhere on all side faces of the obelisk in Figure 25. (We showed in (Kato, 2020) how a plumb was effectively used in the precision shaping of the Great Pyramid.) 

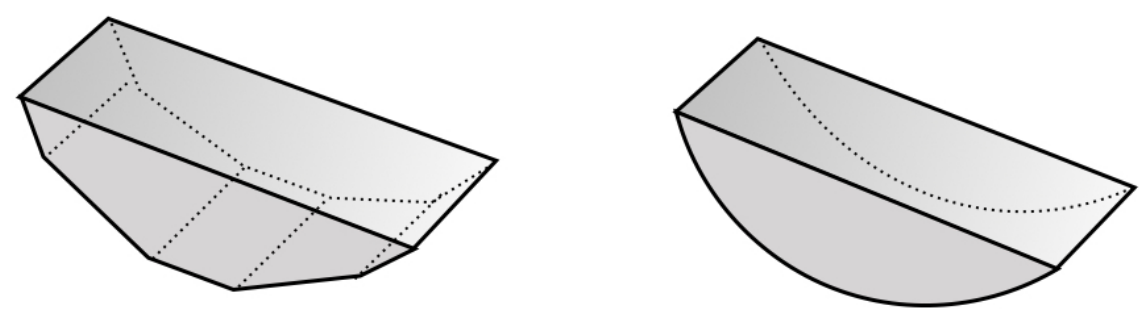

Figure 21. Rockers made from stones of cuboid by chamfer.

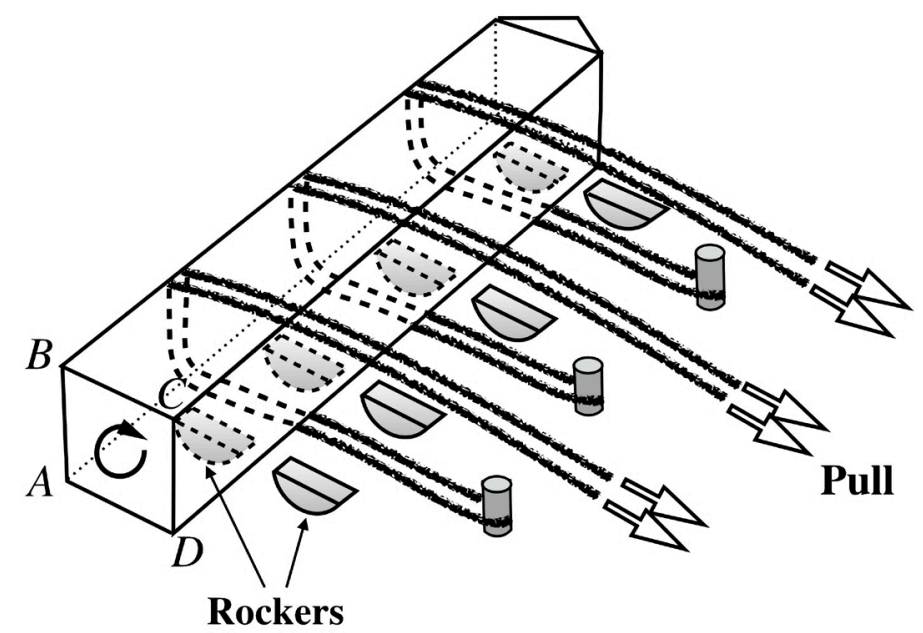

Figure 22. Bird's-eye view of rotation of obelisk.

(1)

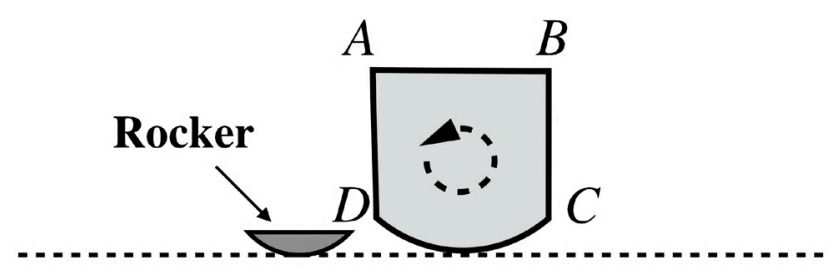

(2)

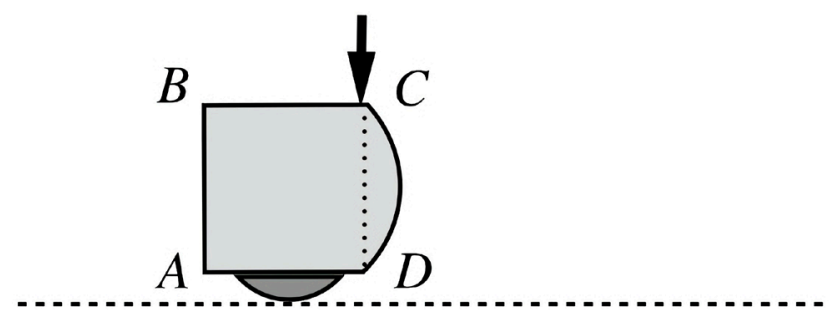

Figure 23. Rotation to remove the belly $C D$.

(3)

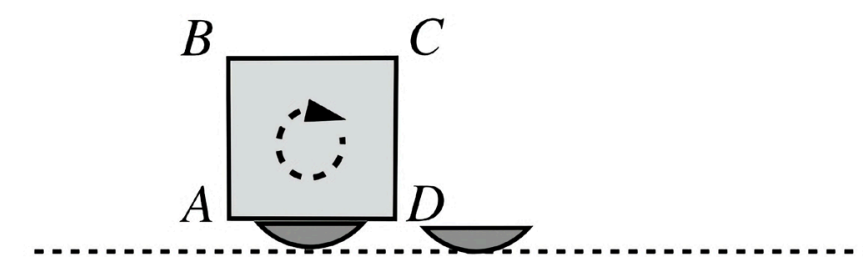


(4)

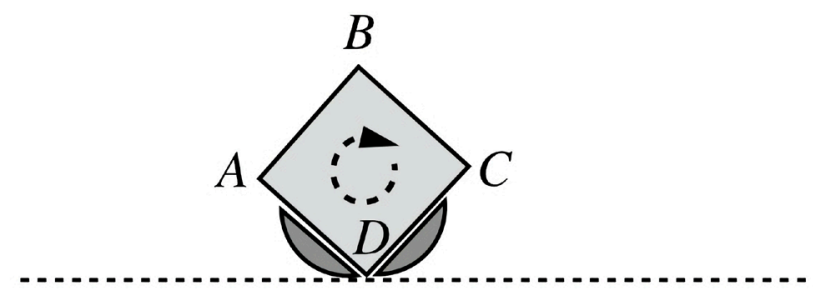

(5)

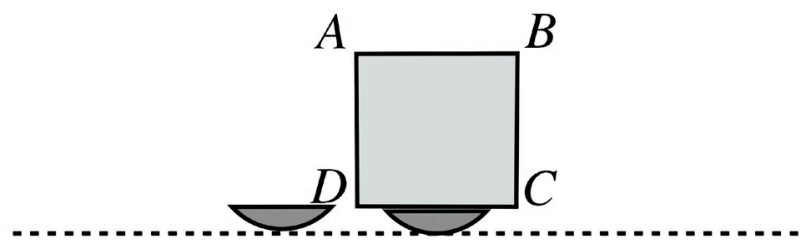

Figure 24. Rotation needed for inscriptions.

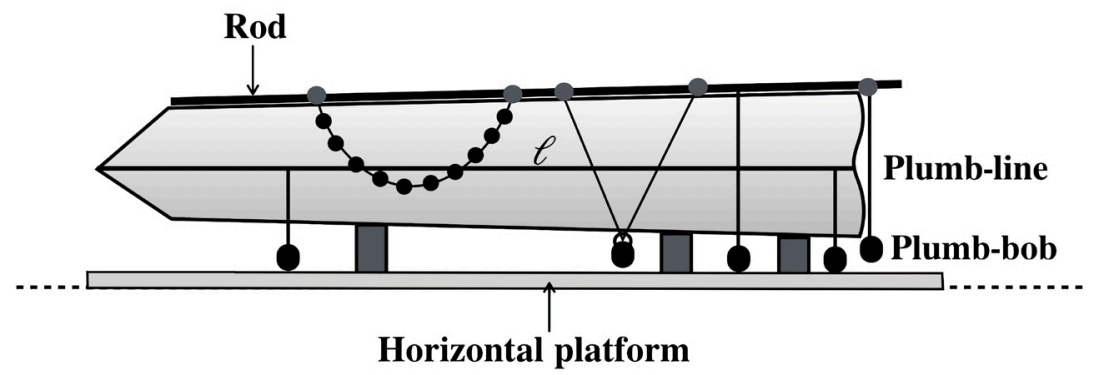

Figure 25. How to examine the flatness of the bottom or side faces of the obelisk, and how to draw a horizontal line.

In order to flatten the faces of the obelisk we propose a blade as in Figure 26 a bit different from the blade of Figure 1. This blade has a feature that the faces $A B C D$ and $E F G H$ are parallel and both of them are dead flat. We can use this blade as in Figure 27 letting its face $A B C D$ contact with a dead flat vertical side of some heavy stone on the right side.

The whole process of the precision shaping of the obelisk would be like as follows. See Figure 28. Let us denote the unshaped obelisk as $T A B C D$ where $A B C D$ is its bottom and $T$ is chosen to be a point which becomes the top point of (the pyramidion of) the shaped obelisk. Next, choose a point $O$ of the bottom face $A B C D$ as a candidate of the center of the bottom square of the shaped obelisk. (Note that the quadrangle $A B C D$ is not yet a square.) We identify the line $T O$ as the central axis of the shaped obelisk. Set a horizontal platform under the obelisk and adjust the line $T O$ to be horizontal measuring the same height of $T$ and $O$ from the platform using a plumb. Then, again using a plumb, draw on the side faces of the obelisk the horizontal lines connecting $T$ and $O$ which surround the obelisk (denoted $\ell$ in Figure 28), and the vertical line passing $O$ (the line $M O N$ in Figure 28). Further draw a line connecting $T$ and $M$ on the upper surface, denoted $m$ in Figure 28. Observe then that the central axis $T O$ is the intersection of the horizontal plane determined by $\ell$ and the vertical plane determined 


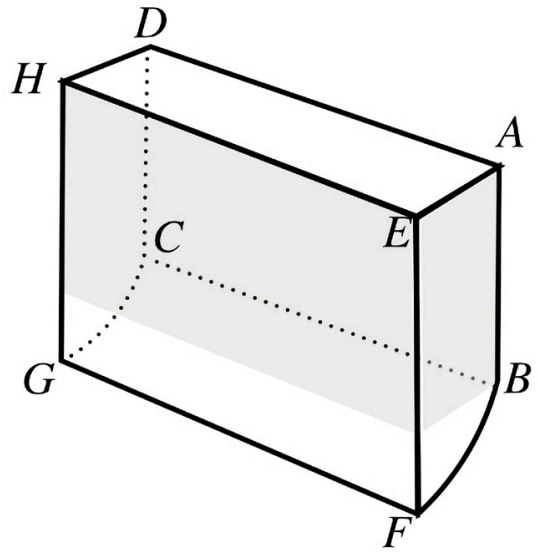

Figure 26. Blade to flatten a surface vertically.

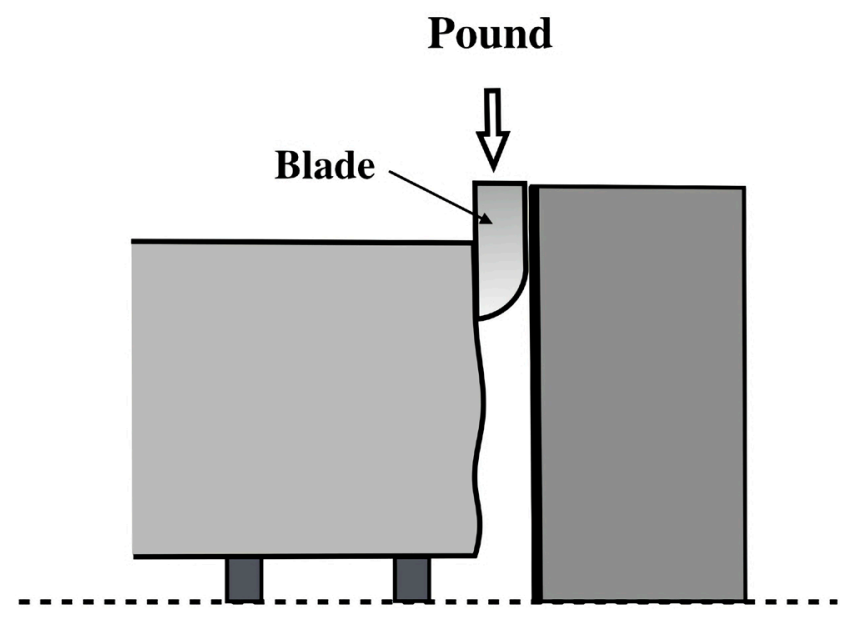

Figure 27. How to level a surface vertically.

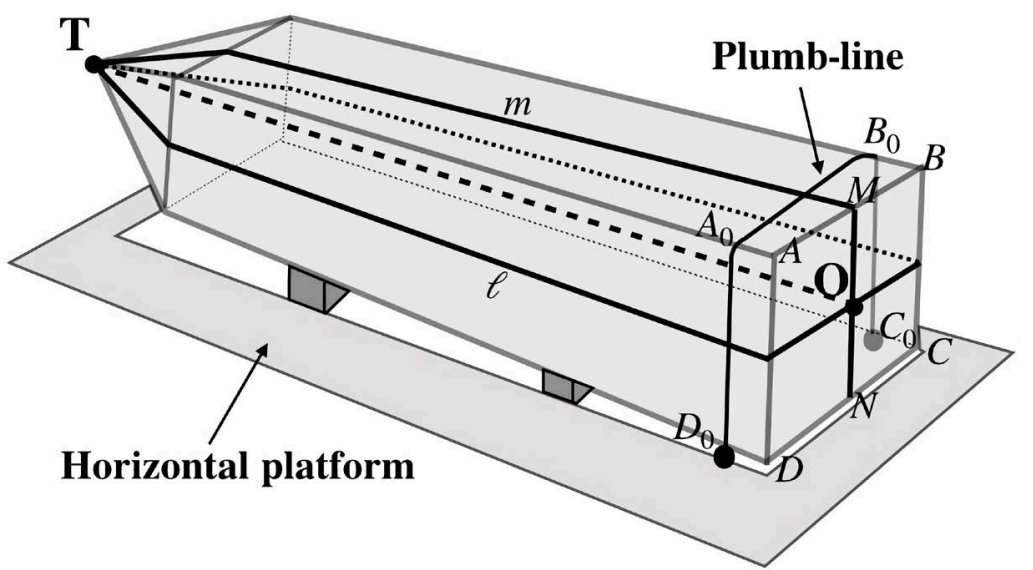

Figure 28. How to draw lines necessary for the precision shaping.

by $m$. Since the upper surface of the Unfinished Obelisk in Aswan looks almost flat, we may assume that the upper plane that $m$ is on in Figure 28 is flat, but note that this upper plane is not horizontal since the obelisk is tapered; what we 
can assume is that the edge $A B$ is horizontal. The bottom face $A B C D$ of the unshaped obelisk need not be perpendicular to the axis $T O$, so we have to correct it. For this purpose we have a very simple useful way, that is, near the bottom hang a plumb $D_{0} A_{0} B_{0} C_{0}$ with plumb-bobs at $D_{0}$ and $C_{0}$ in such a way that the line $A_{0} B_{0}$ is perpendicular to the line $m$, like in Figure 28 . Then, this plumb-line determines the correct bottom face perpendicular to the axis TO. (Of course, this plumb-line should be hung the closest possible to the bottom face $A B C D$; for example, in the case of Figure 28 we may hang it like $A_{0} D_{0}=A D$.) Now suppose we have succeeded in cutting the new vertical bottom face $A_{0} B_{0} C_{0} D_{0}$ using the method of Figure 27 to get a reshaped obelisk $T A_{0} B_{0} C_{0} D_{0}$ with the central axis $T O^{*}$. Then, moving a plumb like $D_{0} A_{0} B_{0} C_{0}$ along the line $m$, we mark the obelisk with lots of lines vertical to the central axis (or either to the line $\ell$ or $m$ ) as in Figure 29 (such marked lines would be quite helpful also in inscriptions); in particular, $A_{1} B_{1}$ and $A_{1} D_{1}$ are the marked lines perpendicular to $m$ and $\ell$, respectively. Now the final step for the precision shaping. Adjust the positions of $A_{0}, B_{0}, A_{1}, B_{1}$ so that $A_{0}, B_{0}$ are equidistant from $m$, and $A_{1}, B_{1}$ are also equidistant from $\mathrm{m}$. Along the adjusted lines $A_{0} A_{1}$ and $B_{0} B_{1}$ cut down vertically to level the side faces $A_{0} A_{1} D_{1} D_{0}$ and $B_{0} B_{1} C_{1} C_{0}$. Next, rotate the obelisk 90 degrees around the axis (like Figure 22), and do a similar thing to level the side faces $A_{0} A_{1} B_{1} B_{0}$ and $D_{0} D_{1} C_{1} C_{0}$, taking care so that $\overline{A_{0} D_{0}}=\overline{A_{0} B_{0}}$ and $\overline{A_{1} D_{1}}=\overline{A_{1} B_{1}}$. This finishes the precision shaping of the obelisk, and after this precision shaping the obelisk would be beautifully decorated with the inscriptions and colors.

Summary of Section 4:

For shaping and decoration we need to rotate an obelisk around its long axis, and such rotation can be done using "rocker," a semi-circular prism made by stone. Use of a plumb with a horizontal platform would accomplish the precision shaping of the obelisk.

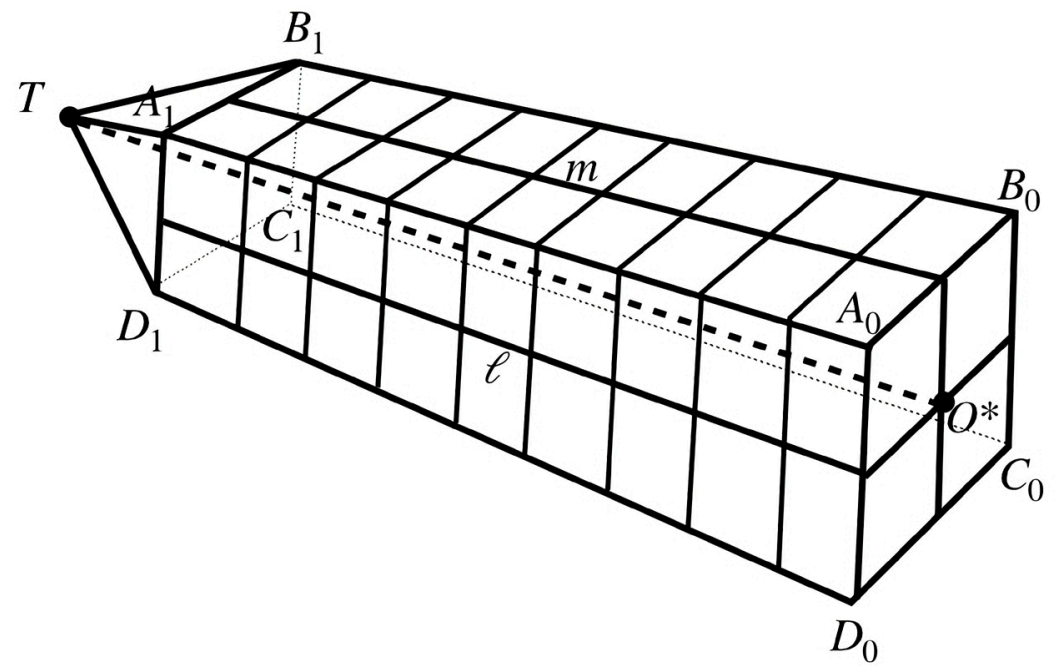

Figure 29. Obelisk whose bottom face was reshaped to be perpendicular to the central axis. 


\section{How to Erect a Pair of Obelisks}

Now we are going to raise the inscribed and colored artefacts carefully. But, the problem is they are quite heavy, and here in this section we present a new idea how to reduce the efforts to raise them. As mentioned in the Introduction, obelisks were originally erected in pairs at the entrance of ancient Egyptian temple, except the single "Lateran" obelisk commissioned by Tuthmosis III, about which we will mention later in Section 7. Though the historical reason to be erected "in pairs" would be religious or aesthetic, we add here an architectural reason in particular to high obelisks:

High obelisks were easier to be erected "in pairs" than to be erected separately, because one obelisk somewhat inclined can serve as a high anchoring post to raise another, as illustrated typically in Figure 35 and Figure 42 which we will explain later.

First of all, to raise a pair of obelisks, we equip each obelisk with a carrier, a "back support" for obelisk, as in Figure 30, and the carrier should be composed of round poles like Figure 31. Recall that we can assume all round poles in the carrier are essentially rotatable, as noted in Section 3. We raise this carrier rather than the obelisk itself. Generally speaking, it would be not so easy to erect an obelisk from a horizontal position, so we believe the ancient Egyptians first tried to incline it a bit using a slope, a traditional idea since the Pyramid Age. In this section we adopt such an idea: Incline each obelisk separately about 30 degrees using a mound of sand or gravel. An alternative way of erection from a horizontal position is proposed in the next section, using a wooden framework instead of a mound of sand. Note that any slope of a mound of sand up to 30 degrees is stable because "the angle of repose" for sand ranges from 30 degrees to 35 degrees (Al-Hashemi \& Al-Amoudi, 2018). We do the inclination by first raising each obelisk up onto a mound of sand, and for this purpose we attach to each obelisk

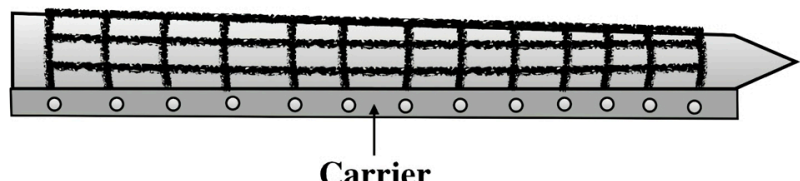

Figure 30. Obelisk with the carrier.

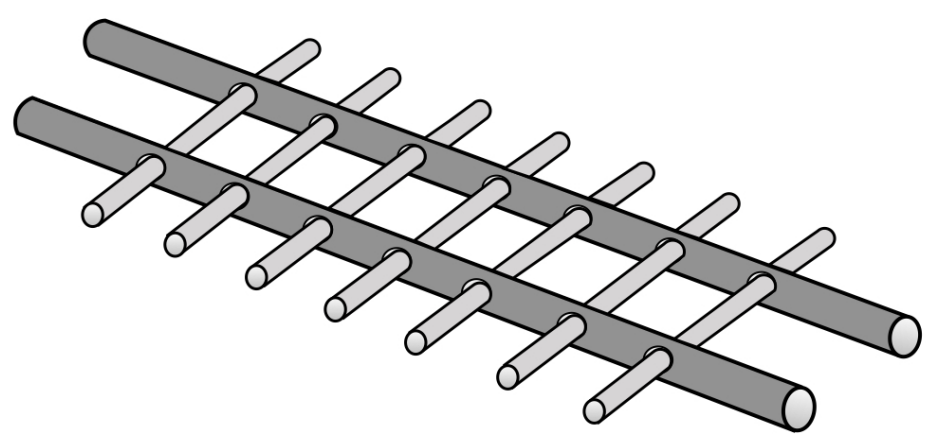

Figure 31. Carrier composed of round poles. 
four rockers, the front ones $R_{1}, R_{1}^{\prime}$ and the rear ones $R_{2}, R_{2}^{\prime}$, as in Figure 32 . (We can get the space for rockers just by removing a few poles from the carrier Figure 31.) These rockers do the same role as the convex belly of the pre-obelisk; compare Figure 32 with (2) of Figure 7. The front rockers $R_{1}, R_{1}^{\prime}$ should be placed under the center of mass of the obelisk, which is just where the center of the belly of the pre-obelisk was and is slightly below the mid point of the obelisk.

Then, the rockers can induce the "pitching" movement to raise an obelisk: See Figure 33. First, insert sand (or gravel) under the obelisk until the four rockers "dip" in sand, and "pitch" the obelisk as in (2). This pitching should be about the rockers $R_{1}, R_{1}^{\prime}$, i.e., about the center of mass of the obelisk. Then sand will flow under the rockers to lift the obelisk a bit. Next, add sand under the obelisk again until the rockers "dip" in sand, and "pitch" the obelisk as in (4). Repeat this process many times until the mound of sand makes its slope of the angle of repose $\alpha \geq 30^{\circ}$ as in (5) of Figure 34. (Each time we can lift the obelisk only at most the height of the rocker, so we have to repeat the process many times.) Then, pivot the obelisk around the rockers $R_{2}, R_{2}^{\prime}$ controlling the pressing-down forces onto the top side $A$ and the bottom side $B$ carefully, and finally we would be able to set the obelisk as in (6) on the slope of the angle about $30^{\circ}$ so that its bottom edge touches properly onto the pedestal (see Section 8), using the carrier as a guide to the pedestal. This process from (5) to (6) would need a great care, should be slow and gentle, and this is why we chose the angle of the slope to be that of repose: The obelisk would not easily slip down on the slope with the angle of repose, and moreover, the rockers as well as the carrier would also work to prevent a sudden slip. Note also that the carrier protects the face of the artefact. The mound of sand would form a cone whose base is a circle with a diameter slightly less than the length of the obelisk, so it might occupy somewhat wide space, but since what we apply is "pitching," it need not be so wide and long as the large sloping embankment described in (Engelbach, 1923: Fig. 27) which is for pulling up an obelisk.

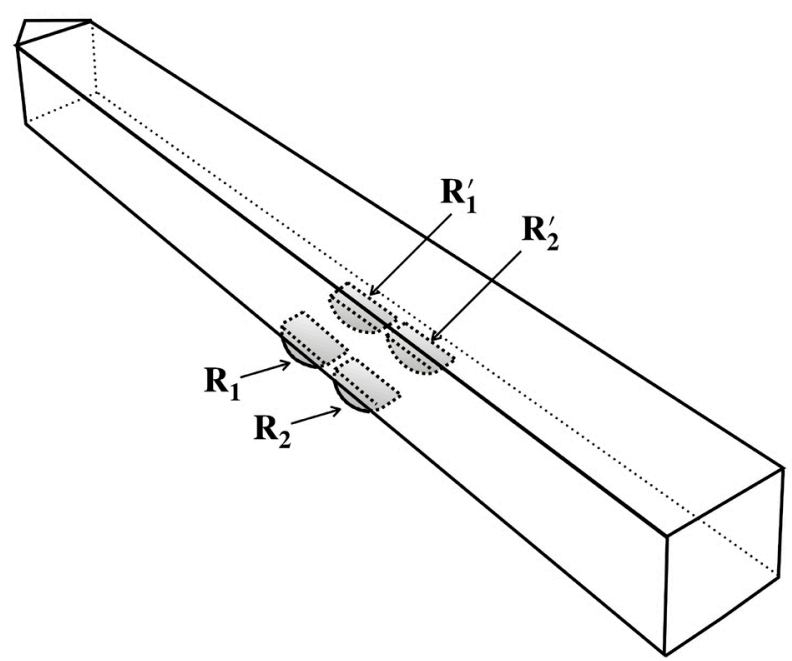

Figure 32. Obelisk with rockers. 
(1)

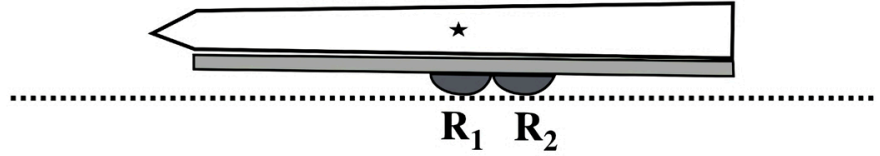

(2)

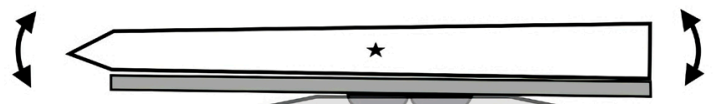

Sand

(3)
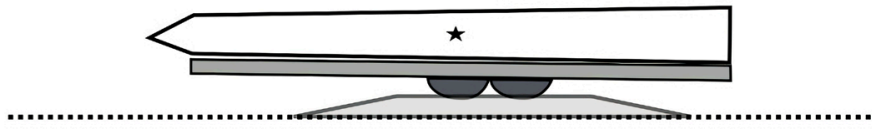

(4)

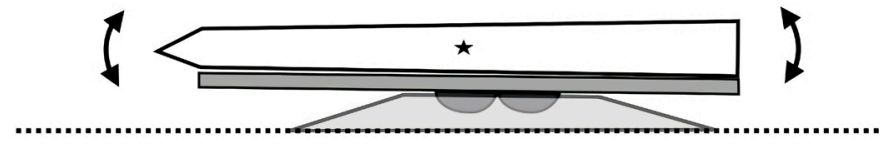

Figure 33. Lifting the obelisk on the mound of sand by pitching, adding sand for the steps from (1) to (2) and from (3) to (4).

(5)

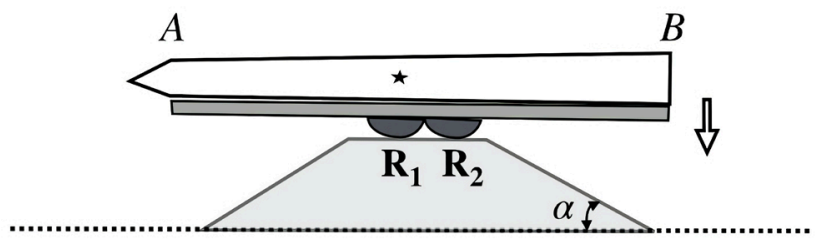

(6)

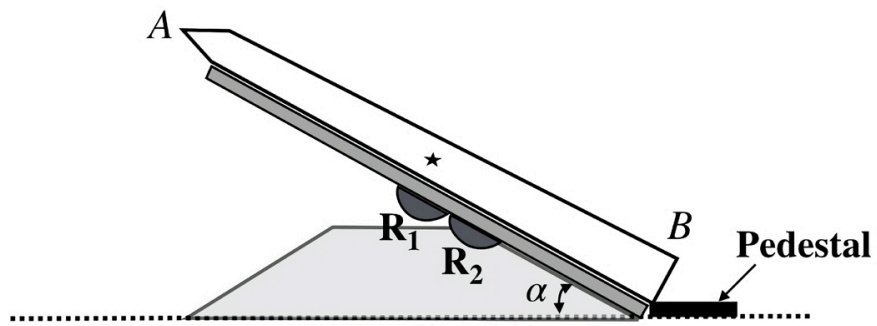

Figure 34. Incline the obelisk up to the angle of repose $\alpha \geq 30^{\circ}$.

Now let $O_{1}$ and $O_{2}$ be two obelisks of the same weight and the same length, and suppose we have succeeded in inclining them about 30 degrees. Then, we erect such a pair of obelisks setting rope as in Figure 35, which emphasizes the carriers and illustrates the use of just one or two ropes though actually we need many many ropes. Essential point is "one obelisk $O_{1}$ can help to erect another $\mathrm{O}_{2}$," as we explain next. Let $P_{1}$ and $P_{2}$ denote the highest horizontal round poles in the carriers of $O_{1}$ and $O_{2}$, respectively. The rope starts from one end $A$, passes around the pole $P_{2}$, then wraps the obelisk $O_{1}$ (just above the pole $P_{1}$ ) and passes again around the pole $P_{2}$, and finally returns to the other end $B$, placed near $A$; let us denote this rope setting simply as

$$
A \rightarrow P_{2} \rightarrow O_{1} \rightarrow P_{2} \rightarrow B
$$




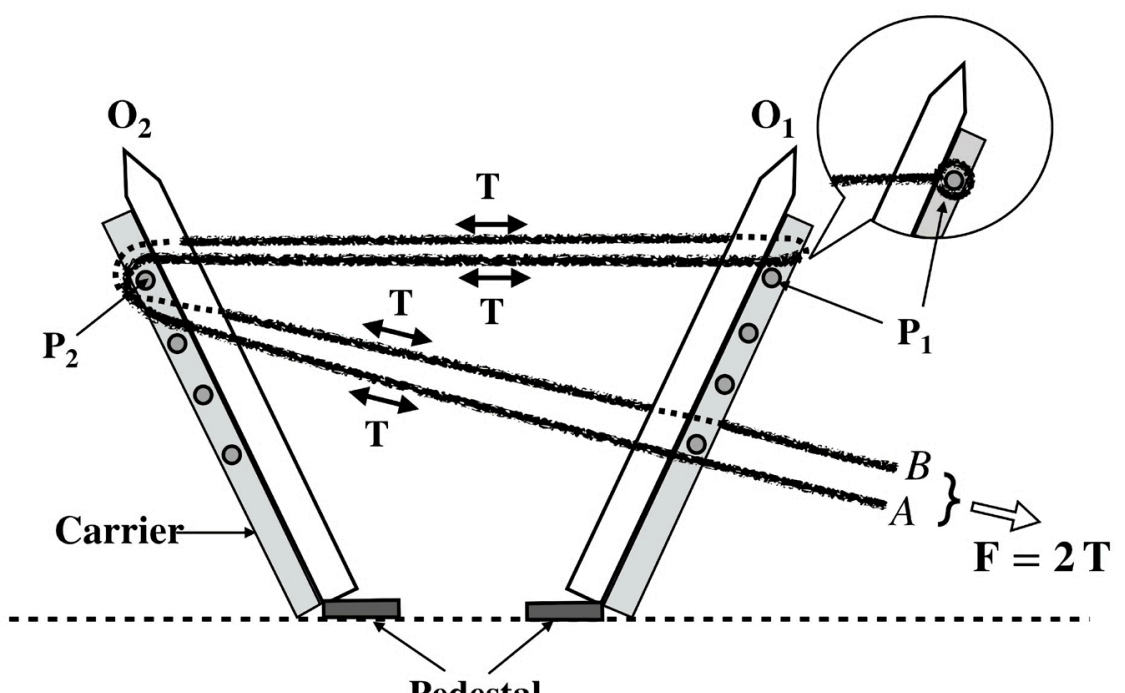

Figure 35. Use of a "Pair" of obelisks: raise one of them, $O_{2}$, keeping a twin $O_{1}$ fixed, utilizing the highest poles $P_{1}, P_{2}$. The rope can be fixed at $P_{1}$ instead of wrapping $O_{1}$ as shown in the quote bubble.

Each free end $A, B$ of the rope should be pulled by the equal power, and then the rope will slide around the rotatable pole $P_{2}$, though will not slide around the obelisk $O_{1}$. So, instead of "wrapping $O_{1}$ " we can fix the rope to the obelisk $O_{1}$ or to the pole $P_{1}$ (as shown in the quote bubble; then we may use two ropes, $A \rightarrow P_{2} \rightarrow P_{1}$ and $\left.P_{1} \rightarrow P_{2} \rightarrow B\right)$.

Let us denote the tension in the rope by $T$. Then, roughly speaking, if the free ends of the rope are pulled by the total force $F=2 T$, the obelisk $O_{2}$ is pulled almost by $2 F$, while $O_{1}$ is pulled only by $F$. So, even when $O_{2}$ starts moving, $O_{1}$ stays fixed. This means that $O_{1}$ acts as an anchoring post, and the pole $P_{2}$ essentially works as a movable pulley reducing almost by half the effort to raise the obelisk $\mathrm{O}_{2}$. (Observe that the rope setting in Figure 35 is essentially the same as Figure 20 if we regard $O_{1}$ and $O_{2}$ as the anchoring post and the stone with the sledge in Figure 20, respectively.) Note that ropes connecting two obelisks are high, and this is the advantage of raising "in pairs." To avoid a bit cumbersome description like Figure 35 let us simplify it into Figure 36, which shows only this side and should be paired with the same setting of rope also on the other side (we also eliminate the illustration of the pedestals). The practical version of Figure 36 would be like Figure 37, where the rope just passes around $P_{1}$ and is fixed to the lower (non-rotatable) pole $P_{3}$. Note that to fix the rope to the pole $P_{3}$ we only need to wind the rope several times around the pole, no need to form the rope into a knot; see for example Figure 19. Mechanically, Figure 37 is the same as Figure 36 since the tension of the rope $P_{1} P_{3}$, directing to or away from the pivot point of $O_{1}$, gives no moment to $O_{1}$. Let us explain the force diagram Figure 38 for Figure 36. Let $W$ be the weight of obelisks $O_{1}, O_{2}$. For $i=1,2$ let $B_{i}$ denote the pivot point on the bottom of $O_{i}$, and we use the same letter $P_{i}$ to denote the position of the pole $P_{i}$. (As for the precise position of the pivot 


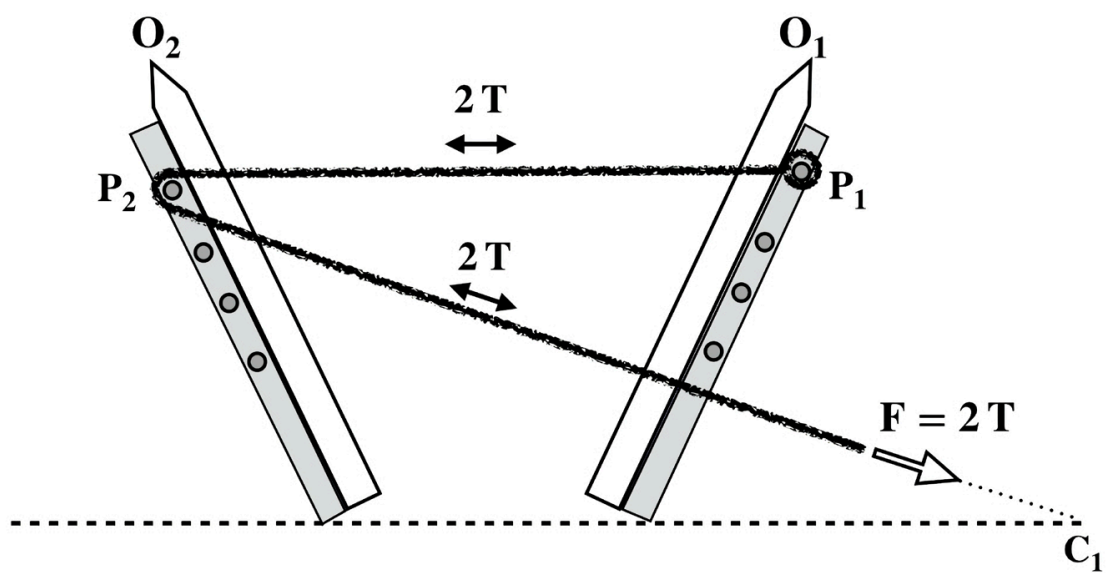

Figure 36. Simplified illustration of Figure 35, where $2 T$ indicates the sum of the tensions of ropes on this side and the other side.

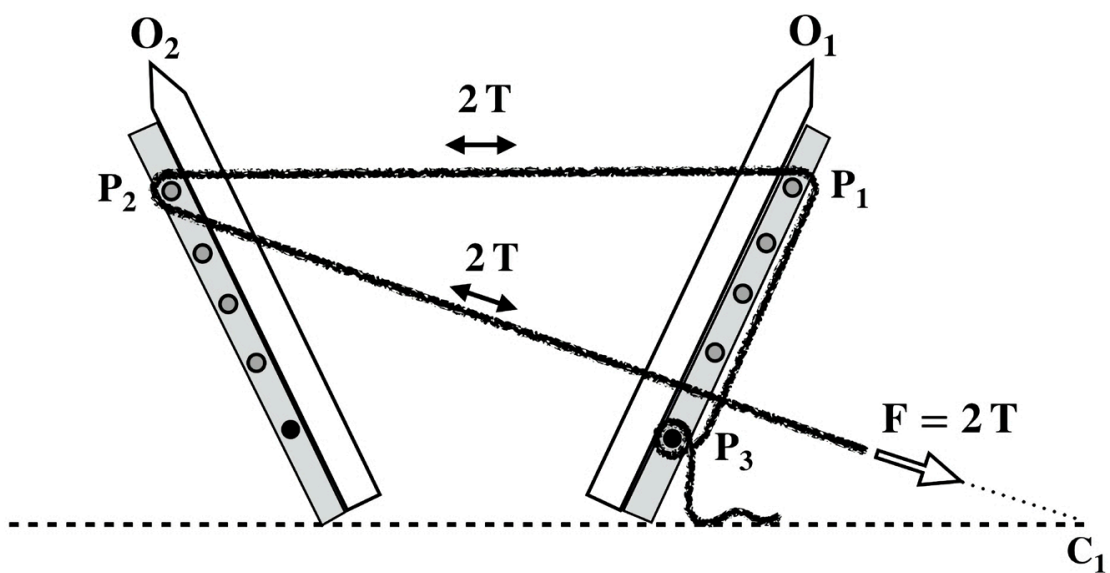

Figure 37. Practical version of Figure 36.

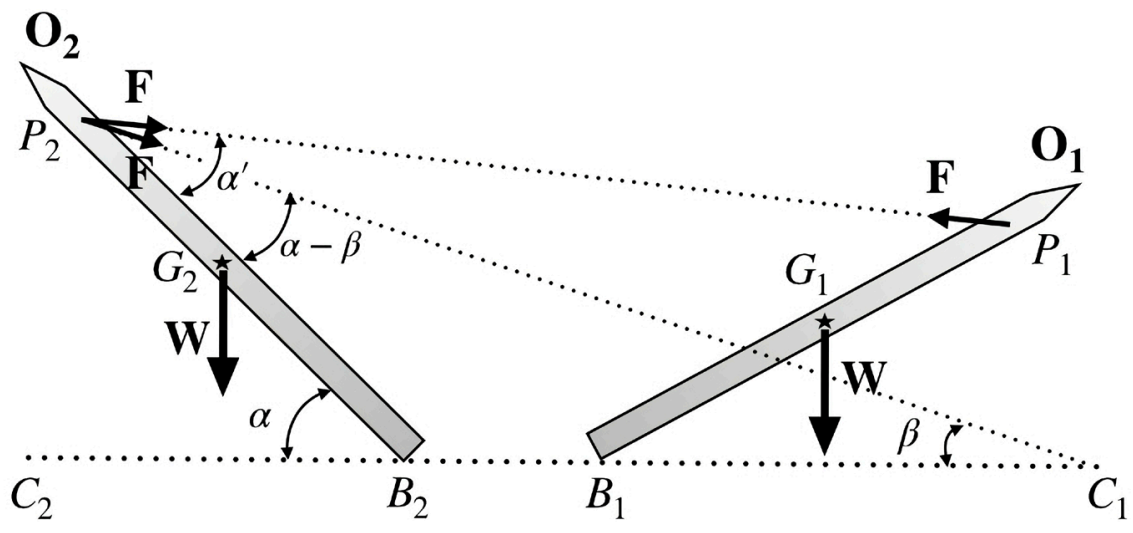

Figure 38. Force diagram of Figure 36.

point $B_{i}$ see Section 8.) It would be natural to assume that the center of mass of $O_{i}$, denoted $G_{i}$, is at the mid point of $B_{i} P_{i}$ so that $\overline{B_{i} G_{i}}=\overline{G_{i} P_{i}}=l / 2$ where $\overline{B_{i} P_{i}}=l$. Suppose that the total pulling force $F=2 T$ was applied at the free ends of the ropes in the direction of $\overrightarrow{P_{2} C_{1}}$. Put 


$$
\angle P_{2} B_{2} C_{2}=\alpha, \quad \angle P_{1} P_{2} B_{2}=\alpha^{\prime}, \quad \angle P_{2} C_{1} C_{2}=\beta .
$$

Let $M\left(B_{2} ; O_{2}\right)$ be the moment of clockwise turn of $O_{2}$ about $B_{2}$. Then we get

(*) $M\left(B_{2} ; O_{2}\right)=F l\left(\sin \alpha^{\prime}+\sin (\alpha-\beta)\right)-W(l / 2) \cos \alpha$.

Let us consider the particular case that the two obelisks were inclined at the same angle $\alpha$. Then we have $\alpha^{\prime}=\alpha$, and the condition $M\left(B_{2} ; O_{2}\right)>0$ to raise $\mathrm{O}_{2}$ is equivalent to

$$
\frac{F}{W}>\frac{1}{2} \cdot \frac{\cos \alpha}{\sin \alpha+\sin (\alpha-\beta)} .
$$

In case $\alpha=30^{\circ}>\beta=15^{\circ}$ this condition becomes

$$
\frac{F}{W}>\frac{1}{2} \cdot \frac{\cos \left(30^{\circ}\right)}{\sin \left(30^{\circ}\right)+\sin \left(15^{\circ}\right)}=0.570 \cdots,
$$

concluding that we need the power about $0.6 \mathrm{~W}$ to raise $O_{2}$. In case $\alpha=45^{\circ}>\beta=20^{\circ}$ we need much less power, only about a third of the weight:

$$
\frac{F}{W}>\frac{1}{2} \cdot \frac{\cos \left(45^{\circ}\right)}{\sin \left(45^{\circ}\right)+\sin \left(25^{\circ}\right)}=0.312 \cdots .
$$

(In case $\alpha=60^{\circ}>\beta=30^{\circ}$ we get $F / W>0.183 \cdots$.) These evaluations tell us that to incline an obelisk up to 45 degrees is the hardest part of its erection, where we should employ any techniques available to reduce the burden of erection. As one of such techniques we next present an effective method to improve the above way. That is Figure 39 such that $P_{1} \rightarrow P_{2} \rightarrow P_{1}^{\prime} \rightarrow C_{1}$ where $P_{1}^{\prime}$ is a pole just below $P_{1}$, and its force diagram is illustrated in Figure 40. The rope $P_{2} \rightarrow P_{1}^{\prime}$ in Figure 39 is higher than the rope $P_{2} \rightarrow C_{1}$ in Figure 36, which is why Figure 39 improves Figure 36. Here we have assumed that the obelisks $O_{1}$ and $O_{2}$ were inclined at the same angle $\alpha \geq 30^{\circ}$, and assume for simplicity that the position of $P_{1}^{\prime}$ is the same as $P_{1}$. Let the direction $\overrightarrow{P_{1} C_{1}}$ of the pulling force $F$ be at the angle $\angle P_{1} C_{1} B_{1}=\gamma$ where $0<\gamma<\pi-\alpha$. Then the moment $M\left(B_{2} ; O_{2}\right)$ of clockwise turn of $O_{2}$ about $B_{2}$ is

$$
M\left(B_{2} ; O_{2}\right)=2 F l \sin \alpha-W(l / 2) \cos \alpha,
$$

which corresponds to the particular case $\alpha=\alpha^{\prime}, \beta=0$ of the above formula ${ }^{*}$ ) for Figure 40. So, the condition $M\left(B_{2} ; O_{2}\right)>0$ to raise $O_{2}$ is

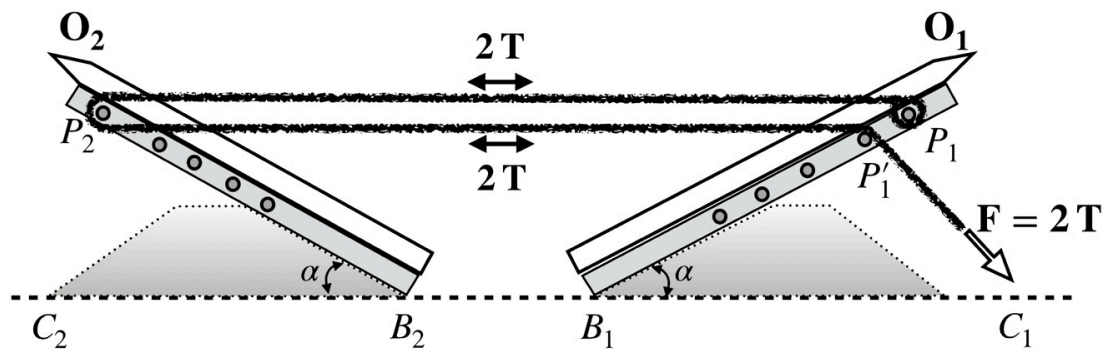

Figure 39. An improved method to Raise $O_{2}$ stabilizing $O_{1}$, where the pulling force $F$ directs to $C_{1}$ on the right side of $B_{1}$. 


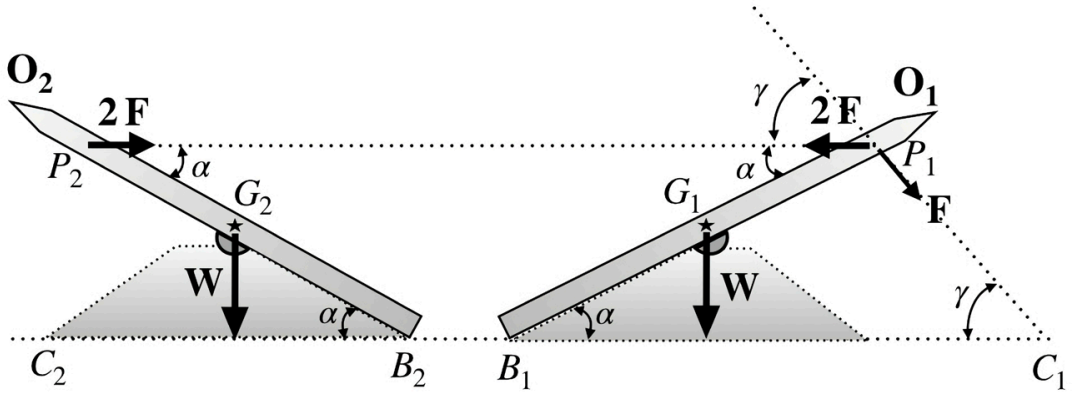

Figure 40. Force diagram of Figure 39 where $0<\gamma<\pi-\alpha$, i.e., $C_{1}$ is on the right side of $B_{1}$.

$$
\frac{F}{W}>\frac{\cot \alpha}{4} .
$$

In case $\alpha=30^{\circ}$ this condition becomes

$$
\frac{F}{W}>\frac{\sqrt{3}}{4}=0.4330 \cdots
$$

telling that we need the power about $0.45 \mathrm{~W}$ to raise $O_{2}$. In case $\alpha=45^{\circ}$ we need much less power, only a quarter of the weight:

$$
\frac{F}{W}>\frac{1}{4} \text {. }
$$

One may wonder about Figure 40 if the pulling force $F$ towards $C_{1}$ might cause some clockwise turn of the obelisk $O_{1}$ about its center $G_{1}$ of mass. Let us show this is not the case. Indeed, let $M\left(G_{1} ; O_{1}\right)$ denote the moment of counterclockwise turn of $O_{1}$ about $G_{1}$. Then we have

$$
\begin{aligned}
M\left(G_{1} ; O_{1}\right) & =2 F(l / 2) \sin \alpha-F(l / 2) \sin (\alpha+\gamma) \\
& =F l \cdot\left(\sin \alpha-\frac{1}{2} \sin (\alpha+\gamma)\right) \geq F l \cdot\left(\sin \alpha-\frac{1}{2}\right) .
\end{aligned}
$$

Hence our assumption $\alpha \geq 30^{\circ}$ implies $M\left(G_{1} ; O_{1}\right) \geq 0$, concluding that the pulling force $F$ towards $C_{1}$ does not cause any clockwise turn of the obelisk $O_{1}$ about $G_{1}$. It would be worth noting that we can use counterweight in Figure 39 which is just the case $\gamma=90^{\circ}$ of Figure 40 .

Further improvements are possible as shown in Figure 41 with the rope setting $P_{1} \rightarrow P_{2} \rightarrow P_{1}^{\prime} \rightarrow C_{2}$, which illustrates the way of raising rather $O_{1}$, not $O_{2}$, fixing $\mathrm{O}_{2}$. Note that Figure 41 is almost the same as Figure 39 except the direction of the pulling force $F$ so that Figure 40 can be a force diagram also for Figure 41 if we replace $C_{1}$ by $C_{2}$ assuming $\pi-\alpha<\gamma<\pi$, i.e., $0<\beta=\pi-\gamma<\alpha$. The moment $M\left(B_{1} ; O_{1}\right)$ of counterclockwise turn of $O_{1}$ in Figure 41 can be evaluated in a similar way to the case of $M\left(\mathrm{~B}_{2} ; \mathrm{O}_{2}\right)$ in Figure 36. In particular, the condition $M\left(B_{1} ; O_{1}\right)>0$ to raise $O_{1}$ in case $\alpha=30^{\circ}>\beta=15^{\circ}$ is

$$
\frac{F}{W}>\frac{1}{2} \cdot \frac{\cos \left(30^{\circ}\right)}{2 \sin \left(30^{\circ}\right)+\sin \left(15^{\circ}\right)}=0.3439 \cdots,
$$




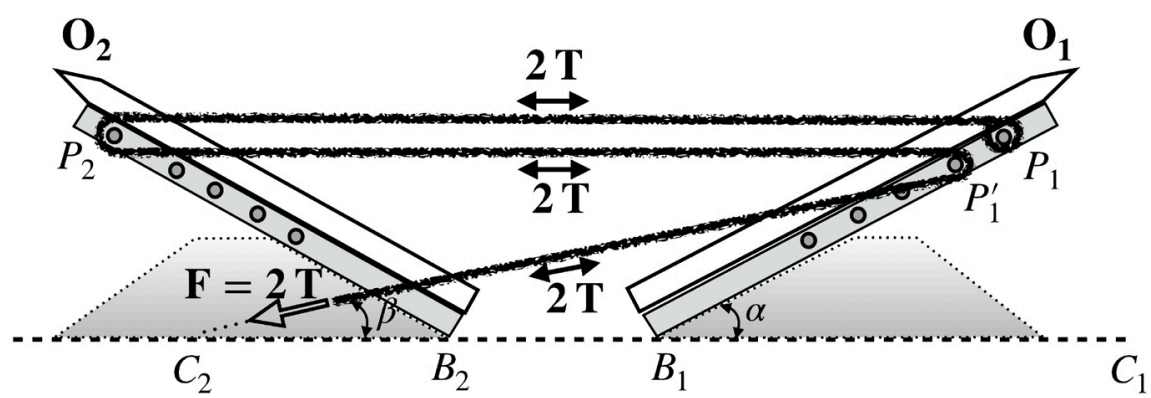

Figure 41. Another effective method (similar to Figure 36), to Raise $O_{1}$ stabilizing $O_{2}$, where the pulling force $F$ directs to $C_{2}$ on the Left side of $B_{1}$.

telling that we need the power about $W / 3$ to raise $O_{2}$. We note that all of the above estimations are just theoretical, and actually we would encounter various reduction of power, including slack in long rope and the energy-consuming friction between rope and pole.

We have shown how to raise one obelisk keeping another fixed. But, note that one obelisk already raised very high compared with another can not serve as an anchoring post; this fact can be convinced if we consider the extreme case of one obelisk stood upright. Therefore, in order to raise both obelisks up to the vertical position effectively we need to employ an alternate raising, one after the other little by little. For example, first, stabilizing $O_{1}$ raise $O_{2}$ a bit higher than $O_{1}$ in the way of (1) of Figure 42, next, stabilizing $O_{2}$ raise $O_{1}$ a bit higher than $O_{2}$ in the way of (2) of Figure 42, etc., which would look like an "almost simultaneous" erection of the pair of obelisks. If both obelisks were inclined sufficiently high, about more than 60 degrees, we would not need so much power to raise them further so that we may employ a simpler method as (3) of Figure 43, where, as long as the difference between the angles $\alpha_{1}, \alpha_{2}$ of obelisks is small, we can choose which to raise, either $O_{2}$ or $O_{1}$ just by decreasing the pulling angle $\beta_{1}$ or $\beta_{2}$, respectively. A simple way to hold both obelisks is shown in (4) of Figure 43. We believe the advantage of raising obelisks "in pairs" is well embodied in Figure 42 and Figure 43. Note that the rope illustrated in (1), (2), (3) and (4) of Figure 42 and Figure 43 can be the same one, that is, these four rope settings are convertible each other. Another "almost simultaneous" erection would be possible by applying the methods of Figure 39 and Figure 41 alternately, just by changing the direction of the pulling force. We also want to remark that we can dispense with extremely long ropes as can be the case of the rope in Figure 44 with the big connecting knots $K_{i}(i=1,2,3)$. Note for example that the knot $K_{1}$ about the mid point between two obelisks does not interfere raising obelisks since it does not move so much from side to side in the above almost simultaneous raising.

\section{Summary of Section 5:}

A pair of obelisks can be raised effectively letting one obelisk act as an anchor in helping another to be raised. First equip each obelisk with a carrier, and then incline them about 30 degrees using a mound of sand since it is quite difficult to 
(1)

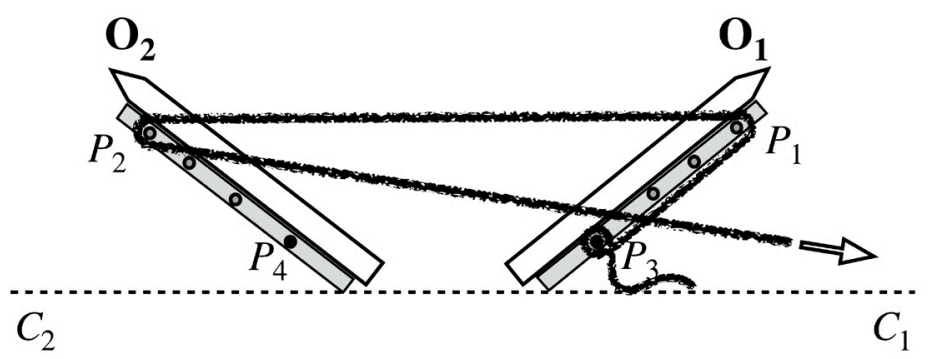

(2)

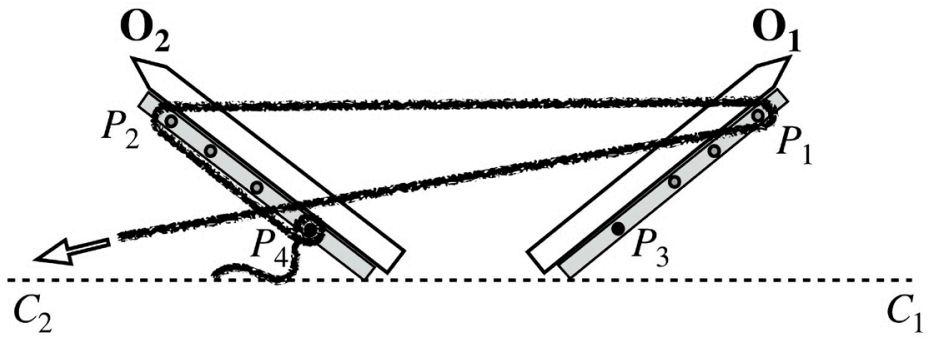

Figure 42. Actual method of raising of a pair of obelisks.

(3)

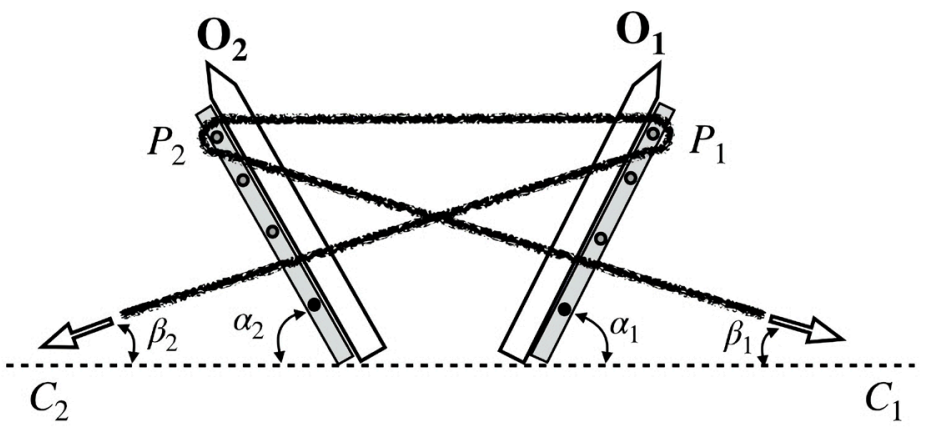

(4)

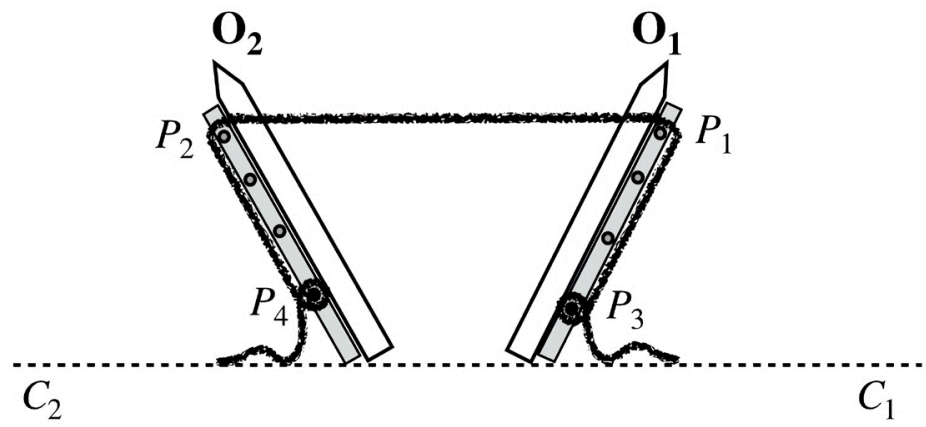

Figure 43. Simple way to raise a Pair of Obelisks (3), and to Hold them (4).

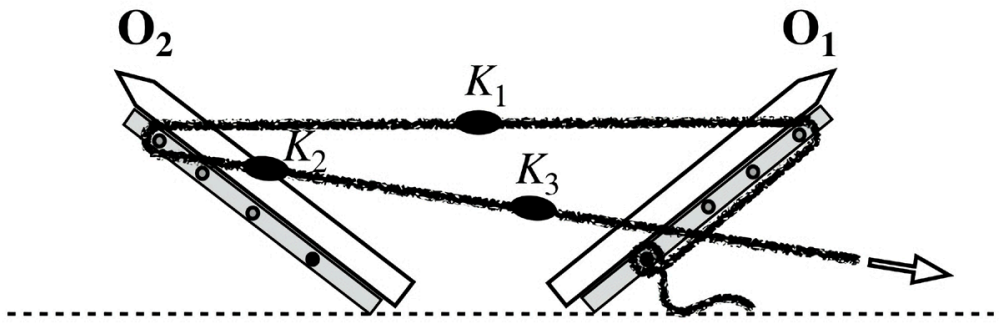

Figure 44. Rope with the connecting knots $K_{1}, K_{2}, K_{3}$. 
raise an obelisk directly from its horizontal position. Passing many ropes high around the two carriers and pulling them, we can raise the pair "almost simultaneously." This way essentially utilizes the mechanism of "movable pulley," and its advantage of raising efforts is about

1) $0.6 \mathrm{~W}$ by applying the method of Figure 42 , or

2) $W / 3$ by applying the methods of Figure 39 and Figure 41 alternately, where $W$ is the weight of each obelisk. Counterweights are also available.

Remark 5.1. As noted before, most of our figures illustrate "mechanism" rather than "actual details." For instance, just one pole like $P_{1}$ or $P_{2}$ in the above figures would be vulnerable to sustain any strong force to raise a heavy obelisk. Therefore, we need to use many poles as well as a stronger carrier. For this purpose we propose the following three adjustments for "actual applications of ropes, poles and carrier."

1) Enclose an obelisk with a framework as in Figure 45, which surely provides many rotatable poles, and affix (non-rotatable) new round poles under the carrier to reinforce it. Note that the carrier or framework can be easily turned into a ladder or scaffold, just by inserting wedges between rotatable poles and holes, which would be quite necessary in setting ropes around poles.

2) Let a rope pass around a multiple of poles like Figure 46, where a rope passes around three poles $P_{1}, P_{1}^{\prime}$ and $R$; the pole $R$ is a newly added one in the above (1) and is not rotatable, so it should be well greased or preferably, some bronze tube should be inserted between the rope and the pole $R$, as in Figure 13 .

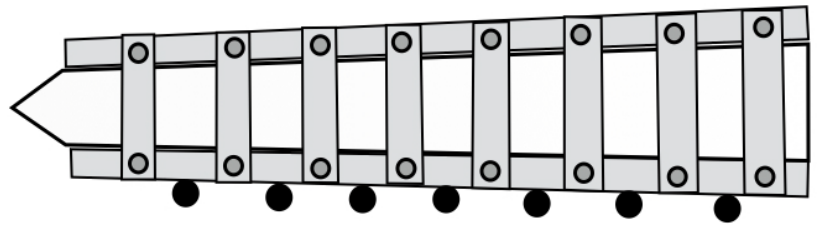

Figure 45. Enclosure with framework and reinforcement of the carrier by affixing poles, colored black. (Side view)
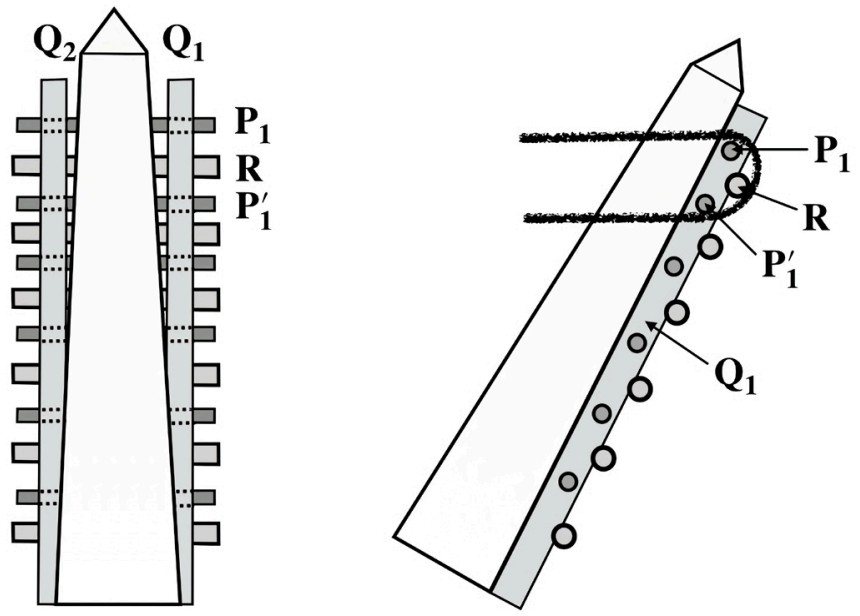

Figure 46. Passing a rope around a multiple of poles. (Left: Front view, Right: Side view) 


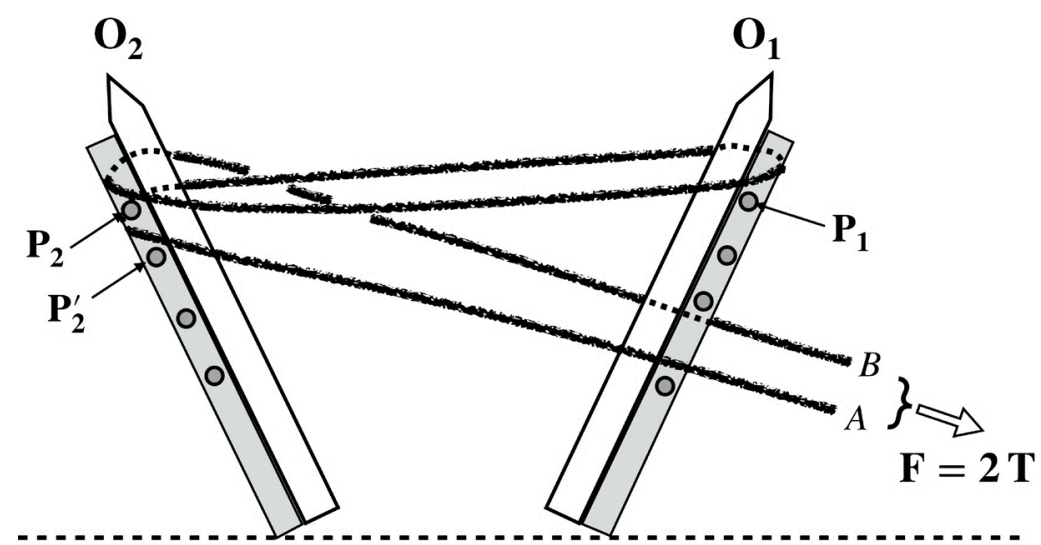

Figure 47. Passing a rope around the long round poles (colored grey) of the carriers.

3) Let also long poles (denoted $Q_{1}$ and $Q_{2}$ in Figure 46) act as pulleys like Figure 47: $A \rightarrow O_{2} \rightarrow O_{1} \rightarrow O_{2} \rightarrow B$, where the rope first passes around the two long poles behind the obelisk $O_{2}$ between $P_{2}$ and $P_{2}^{\prime}$, then around $O_{1}$ above $P_{1}$, and goes back again to $O_{2}$ passing around the long poles above $P_{2}$. Since these long poles are not rotatable, they should be taken care of lubrication or bronze tube like the case of $R$ in the above (2). Note that the horizontal poles $P_{1}, P_{2}, P_{2}^{\prime}$ are just for the rope to keep its position.

\section{An Alternative Way to Erect a Pair of Obelisks, Using Wooden Framework}

In the method of Section 5 we first inclined a pair of obelisks about 30 degrees using a mound of sand. But such a mound of sand occupies somewhat wide circular space as noted in Section 5. Though this was probably no problem at the beginning age of High Obelisks when the erection spot was not crowded with other buildings, it would become problematic as the erection spot became tighter. Recall that in the Great Temple of Amun, Karnak, there were about 20 many obelisks in ancient Egyptian times. So, we believe the ancient Egyptians needed new ideas to get around this difficulty. Here in this section, we next propose an alternative simple way to erect a pair of obelisks from the horizontal position, which uses wooden framework instead of a mound of sand and need not occupy a wide space. Enclose each obelisk with a wooden framework as illustrated in Figure 48 , built by piling up the basic structure $A B C$ as in the quote bubble, which looks like a double sided stepladder. Then a pair of obelisks can be raised in the way of Figure 49, similar to Figure 39, where one end of the rope is fixed to the framework enclosing $O_{1}$ and the other free end is pulled down (so, here we may attach some counterweights). Note that the framework provides lots of poles for ropes to pass around so that we would be able to use many ropes effectively in many ways. The great advantage of this method is that obelisks can be raised from the horizontal position, and consequently, we can place the bottom of the obelisk in the best position w.r.t. the pedestal (see Section 8).

A bit simplified force diagram of Figure 49 is shown in Figure 50, where $S_{i}$, 


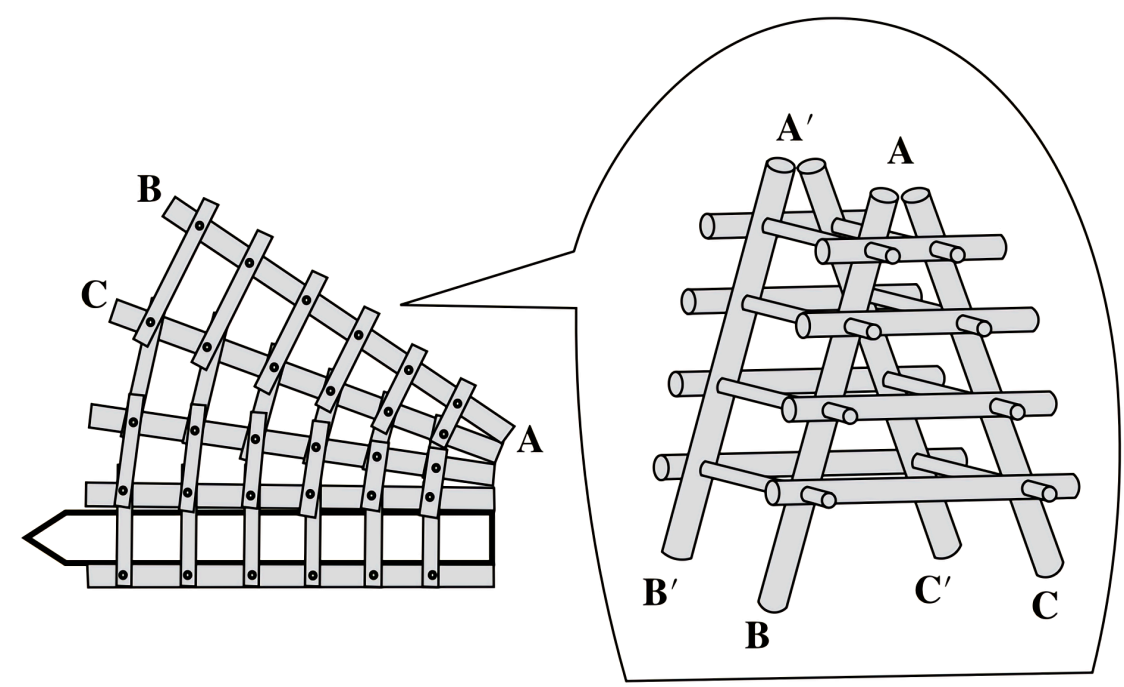

Figure 48. Wooden framework making an obelisk easier to be raised.

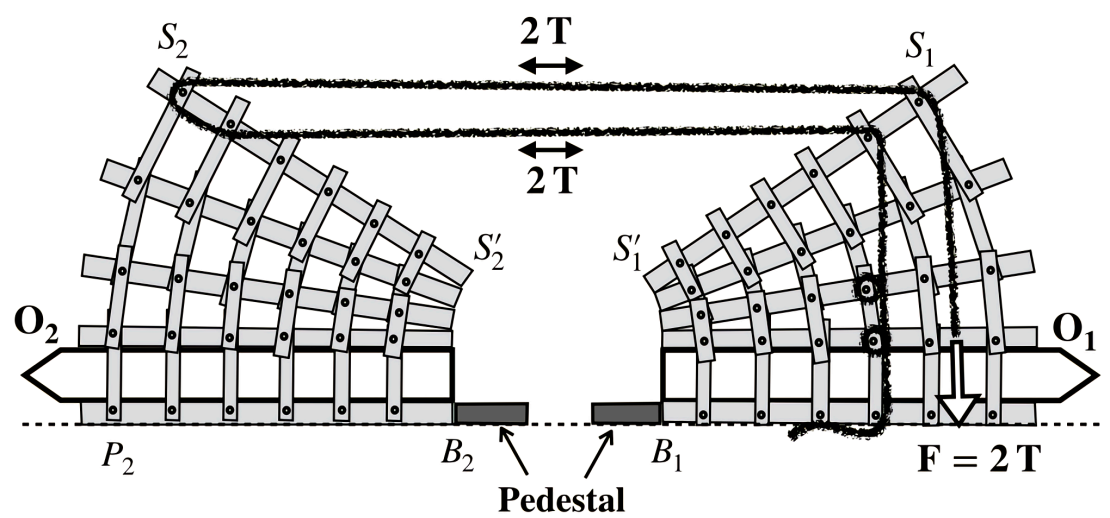

Figure 49. How to raise $O_{2}$ stabilizing $O_{1}$, using the wooden frameworks of Figure 48.

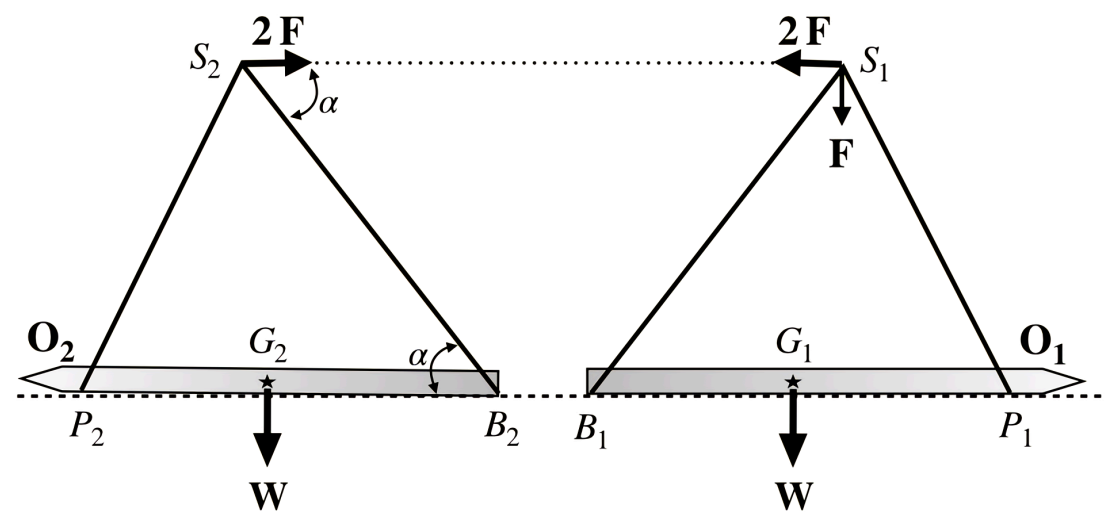

Figure 50. Force diagram of Figure 49.

for $i=1,2$, denotes the position of the highest horizontal pole of the framework of $O_{i}$, and we put $\angle S_{i} B_{i} G_{i}=\alpha$. Let $\tilde{O}_{i}$ denote the obelisk $O_{i}$ together with its framework, and let us do a rough estimation of $M\left(B_{2} ; \tilde{O}_{2}\right)$, the moment of clockwise turn of $\tilde{O}_{2}$ about $B_{2}$. We treat $\tilde{O}_{i}$ as a "rigid body," and neglect the 
weight of framework since the wooden framework would be light enough compared with the heavy obelisk. We also assume that $\overline{S_{2} B_{2}}=\overline{P_{2} B_{2}}=l, \overline{G_{2} B_{2}}=l / 2$. Then,

$$
M\left(B_{2} ; \tilde{O}_{2}\right)=2 F l \sin \alpha-W(l / 2) .
$$

So, the condition $M\left(B_{2} ; \tilde{O}_{2}\right)>0$ to raise $\tilde{O}_{2}$ or $O_{2}$ is

$$
\frac{F}{W}>\frac{1}{4 \sin \alpha} \text {. }
$$

For instance, let us consider the case that the elevation angle of the highest long pole $S_{2} S_{2}^{\prime}$ is $45^{\circ}$, and assume that $\alpha=45^{\circ}+10^{\circ}=55^{\circ}$. Then we have

$$
\frac{F}{W}>0.3051 \cdots
$$

Though this is a quite rough estimation, it would be safe to conclude that the power to raise $\mathrm{O}_{2}$ with the framework is at most $W / 3$. This advantage is not so bad as an erection from the horizontal position, comparing with the same conclusion $W / 3$ about the case of erection of $O_{1}$ in Figure 41 from the position $\alpha=30^{\circ}$. Note that the rope setting of Figure 49 corresponds to Figure 39, and so, more advantage we can get if we utilize more effective rope setting like Figure 41 instead of Figure 39.

Summary of Section 6:

A pair of obelisks can be raised effectively from the horizontal position using wooden framework. Enclose each obelisk with a high wooden framework extending the carrier. Passing many ropes high around the two frameworks and essentially utilizing the mechanism of "movable pulley," we can raise the pair "almost simultaneously" from the horizontal position with the great advantage, more than $W / 3$. Many counterweights can be hung on these frameworks.

\section{Erection of a Single Obelisk}

Now we consider a single obelisk, how to raise it. All obelisks were erected in pairs until the commission by Tuthmosis III: (Blyth, 2006) "For his fifth sed-festival, the king (Tuthmosis III) commissioned the single "Lateran" obelisk, but it would appear that he died while it was still being decorated, and it was left to Tuthmosis IV to erect it at the spot intended for it by his grandfather." This became the first case of a single obelisk being erected. Though the motivation of erection of high obelisks would be mainly for king's dignity, we believe that their erection had great effects in leading high technology in ancient Egypt, so that it can be well compared with launching space rockets in modern times. So, we suspect that one of many reasons why Tuthmosis III commissioned a single obelisk is to inspire a technical challenge for architects, as he observed that hitherto method of erection of obelisks somehow took an advantage of "being a pair." Though we do not know the true solution by Tuthmosis IV who did accomplish the erection of the single "Lateran" obelisk, we propose here our feasible solution when we can find and utilize some high building near the spot of erection. 
For example, in case we can find a pylon near the erecting spot, we can utilize it. Recall the fact that pylons are very high, for example, at the entrance of Luxor Temple an obelisk of 25 meters high stands just before the pylon of 24 meters high. So, assume that we want to erect an obelisk just before a pylon high enough. Then we can utilize it as in Figure 51 to raise the obelisk $O_{2}$. On the top of the pylon were rockers with grooves, as illustrated in the quote bubble, which act as simple pulley to redirect the pulling force. Of course, the grooves of the rockers should be well greased, and about the use of such a semi-cylindrical device see (Isler, 2001: p. 262). It should be noted that, even if we can see nowadays an obelisk just before a pylon, that does not mean the pylon was utilized since the obelisk might be erected before the pylon was built. When we can not find a pylon or its substitute near the erecting spot, instead we may need to construct some high simple building. Note that the wooden framework in Figure 48 is itself a high building so that we may utilize it as in the way of Figure 52, which is

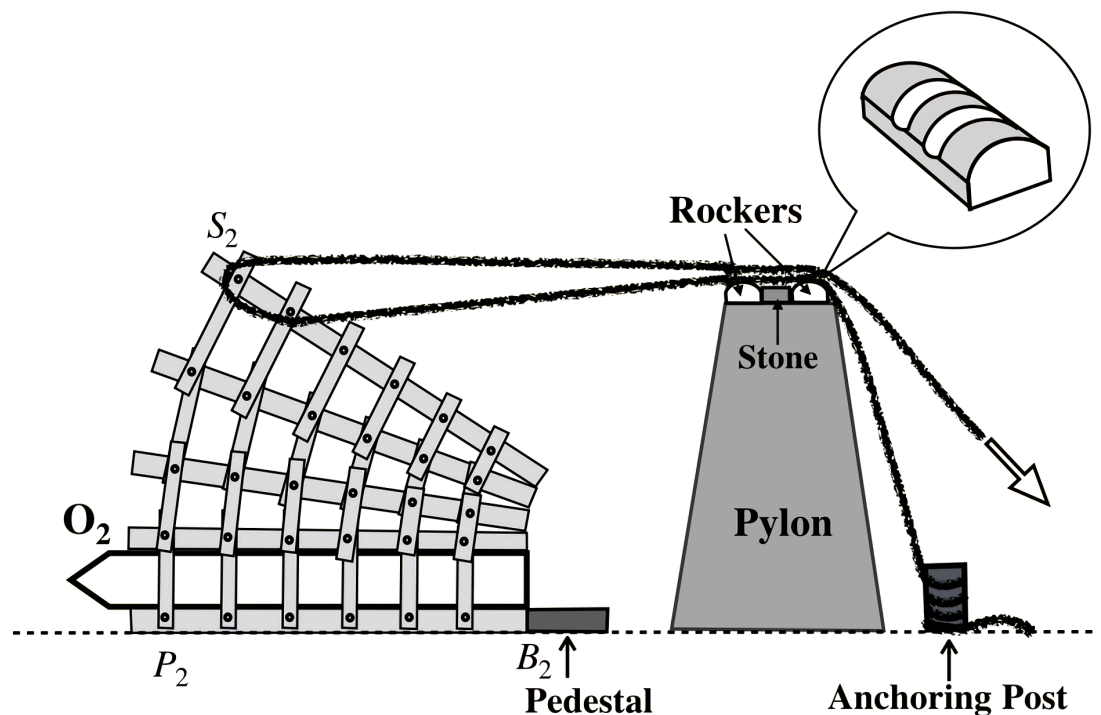

Figure 51. Use of pylon to raise an obelisk. rockers on the top of the pylon shoud have grooves as in the quote bubble.

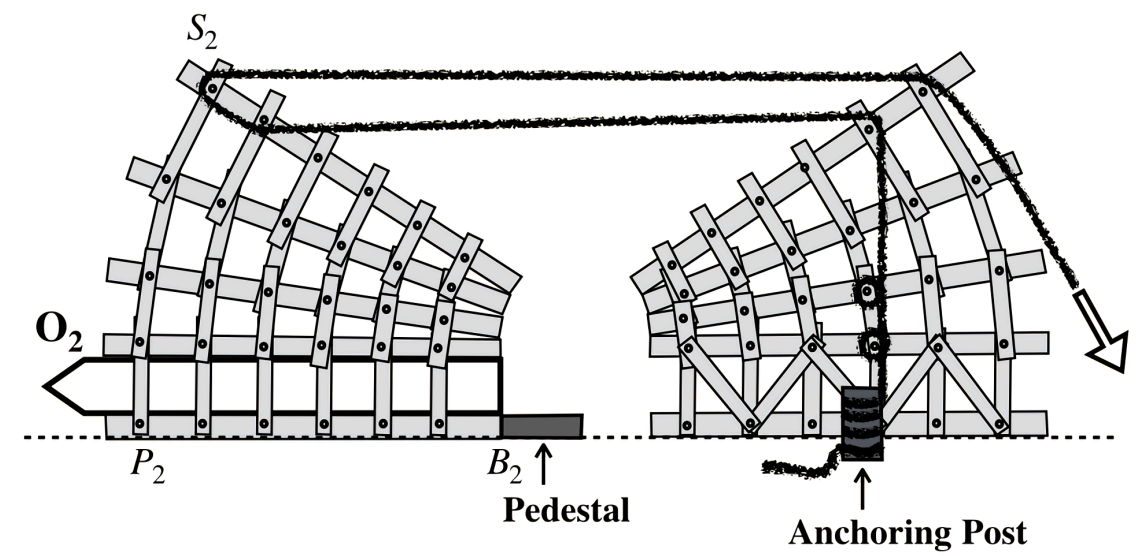

Figure 52. The wooden framework for raising a single obelisk. 
almost the same as Figure 49 except that the obelisk $O_{1}$ is deleted. In either case of Figure 51 or Figure 52 the calculation of the moment of clockwise turn of $\mathrm{O}_{2}$ about $B_{2}$ is almost the same as the case in Section 6 so that the power to raise $O_{2}$ is about $W / 3$.

Summary of Section 7:

The method of Section 6 can be easily transferred to the case of erection of a single obelisk, just by replacing one framework (enclosing one obelisk) in Section 6 with some suitable high building or scaffolding. Some scaffolding like the wooden framework on the right side of Figure 52 might be possible to be built even at a tight spot.

\section{How to Set an Obelisk Precisely on Its Pedestal}

Finally, we explain an important task how to place an obelisk onto its pedestal precisely. Recall that a narrow groove (also called "notch" or "slot") always runs along one side of the surface of the pedestal for obelisk, and it may be used as a turning groove to pivot on, placing the edge of an obelisk so as to engage in this groove. About this groove, Engelbach noted that:

(i) (Engelbach, 1922: p. 52) "In all the other pedestals (i.e., other than the obelisk of Hatshepsowet) I have examined, where the obelisks have apparently come down so as to bear on the inner edge of the slot, the edge is very distinctly crushed."

(ii) (Engelbach, 1923: pp. 67-68) "The obelisk of Hatshepsowet at Karnak has come on to its pedestal askew, and has never used the notch at all, as its edge is quite sharp and unburred. This shows that the notch was not an essential for the ancient method."

Though the assertion (ii) is a bit contrasting to the fact (i), we can see at least from (i) and (ii) that in most obelisks the groove on the pedestal was used as a turning groove to pivot on, but some new way, not to use the groove heavily, was employed in the case of the obelisk of Hatshepsowet. This means the way of erection of obelisks had evolved over time. As explained before in Section 5, we believe they first tried the method of Section 5, a traditional way to use slope to incline obelisks about 30 degrees and used the groove as a turning groove. But this method caused some severe damage to the edge of the base of obelisk or the inner edge of the groove of the pedestal due to the heavy weight of the obelisk as stated in the above (i), and this was of course not desirable for the artefact obelisk. So, to improve this defect, we believe they have invented another way like the method of Section 6 of wooden framework and some alternative way to avoid the heavy use of the groove. Even they might have combined the two methods, first inclining obelisks a bit and then affixing the framework.

Here we propose an alternative way of placing an obelisk onto its pedestal which utilizes rockers and does not depend heavily on the groove. Affix four rockers $R_{1}, R_{1}^{\prime}, R_{2}, R_{2}^{\prime}$ to the bottom surface of an obelisk as in Figure 53 like the case of Figure 32. This attachment need not be so tight, and can be done by 


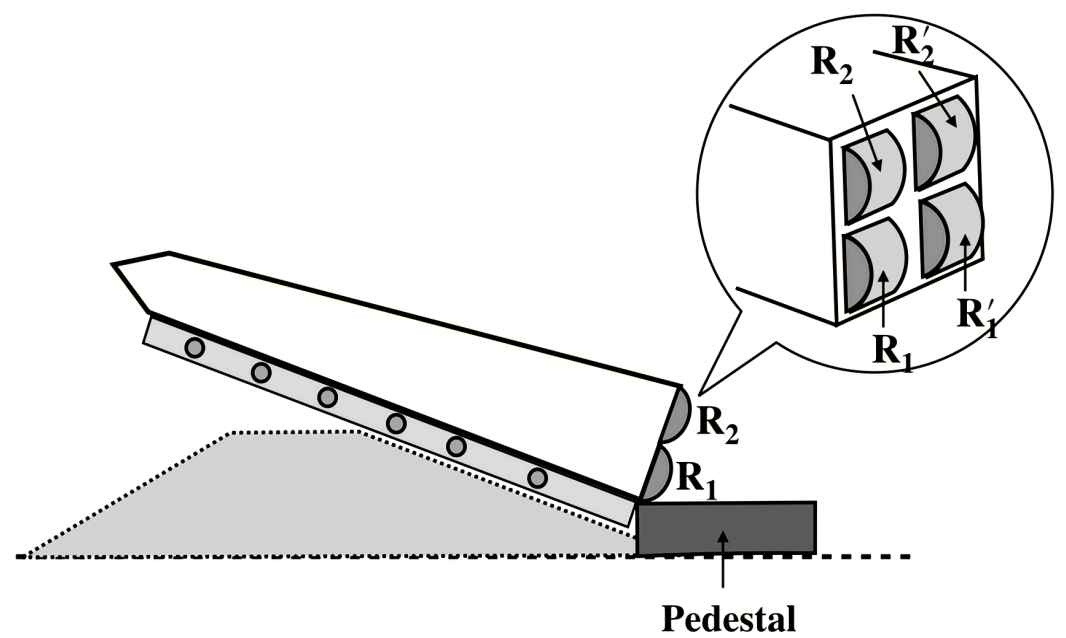

Figure 53. Attaching rockers on the bottom of an obelisk.

(1)

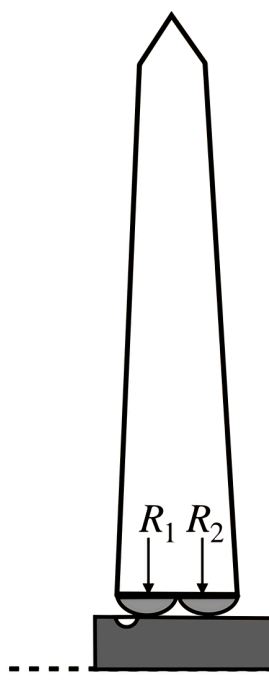

(2)

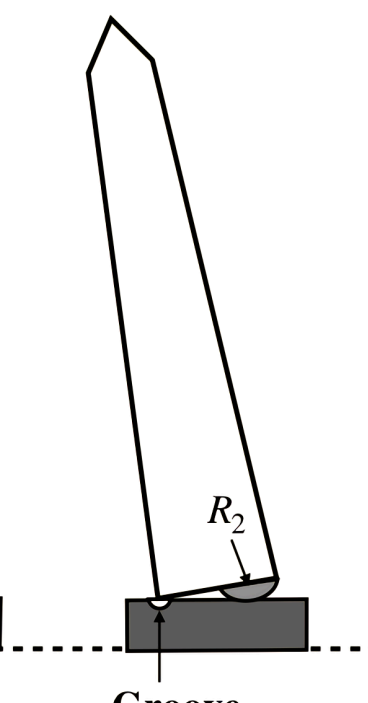

Groove
(3)

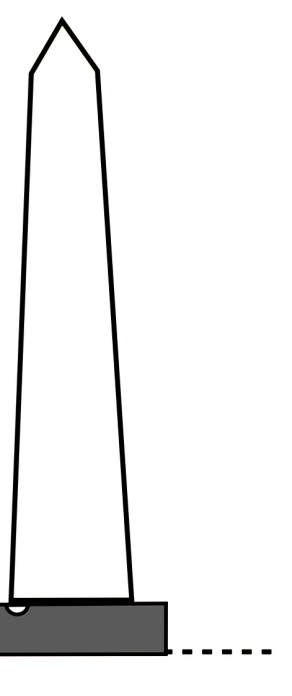

\section{(1)}

Figure 54. How to remove the rockers to complete the setting of an obelisk onto the pedestal.

using ropes with some wooden frame work around the bottom of the obelisk. (Instead of attaching, it may even be possible to place the rockers at the proper positions on the pedestal.) Then the rockers $R_{1}, R_{1}^{\prime}$ (precisely, the contact points of the rockers and the pedestal) become pivot points for erection of the obelisk. Now suppose the obelisk stood upright on the four rockers as shown in (1) of Figure 54, which reminds us Theodosius' obelisk in Istanbul supported by four bronze cubes (Favro, 2018: p. 24). (In case of the erection of Theodosius' obelisk such four bronze supports in spaced relation from the top of the pedestal were necessary in order to withdraw the lowering slings (Isler, 1976: p. 32).) Then we can take away those four rockers in the following way. First, remove $R_{1}, R_{1}^{\prime}$ by inclining the obelisk slightly rightwards, and descend the corres- 
ponding edge of the obelisk into the groove as in (2). Next, remove $R_{2}, R_{2}^{\prime}$ inclining the obelisk slightly leftwards pivoting on the edge at the groove. Finally, let the obelisk land softly onto the pedestal to settle down it upright as in (3). We want to point out additionally that we better use some chocks at the pedestal to prevent it from sliding due to the heavy weight of the obelisk. This precise placing of obelisk on the pedestal completes the erection of the artefact obelisk.

Summary of Section 8:

In order to place an obelisk onto its pedestal precisely, the ancient Egyptians first used the groove on the surface of the pedetal as a turning groove to pivot on. But this caused severe damage to the edge of the base of the artefact obelisk so that later they would have found a new improved method to utilize rockers which does not depend on the groove heavily.

\section{Concluding Remarks}

In Section 5 and Section 6, we proposed two new kinds of methods to raise obelisks. As explained in Section 8, we believe, the ancient Egyptians first tried the method in Section 5 which is essentially the raising from the inclination of 30 degrees assisted by a mound of sand, and later found the more effective alternative way in Section 6, an erection from the horizontal position assisted by a wooden framework. These two methods may look different, but mechanically they are quite similar in the following sense. Both intended to get around the difficulty of raising an obelisk directly from its horizontal position. The mound of sand inclined the carrier in Section 5, while the wooden framework in Section 6 extended the carrier to get the inclined upper part, that is, $S_{2} S_{2}^{\prime}$ in Figure 49. As is well known, Queen Hapshepsut remarkably pioneered the architectural techniques, so we suspect that the effective method of Section 6 was already found during her reign. (Engelbach's note (ii) in Section 8 indicates that Queen Hapshepsut tried some new method of erection of obelisk.) Use of wooden framework is generally quite effective since we can increase its power by extending it to use more ropes whenever needed. Recall that we utilized wooden framework also for moving the pre-obelisk Figure 14 .

Most of our ideas in this article stem from our former paper (Kato, 2020), where the ideas of "forerunner of pulley, rocker, and plumb" were already introduced to explain the construction of the Great Pyramid. It should be well observed that it is quite natural to accept some simple kind of power-multiplying principle such as "forerunner of pulley," facing up the vast quantity of stones used for the Great Pyramid and the immense weight of the Unfinished Obelisk (over 1000 tons). We believe the ancient Egyptians knew empirically various methods, but they did not abstract from them some concept or principle like "pulley." We hope this article with the former one could "excavate" the architectural techniques in ancient Egypt buried in the passage of time.

Let us finally observe the essential features of the following three principal means employed in this article. 


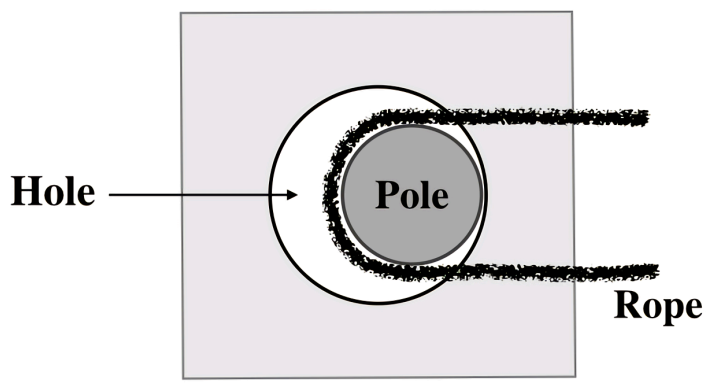

Figure 55. Simple device of a pole rotating in a hole, or "plain bearing" (side view).

1) System of Round Poles compounded with Ropes and Anchoring Posts:

The main reason we have introduced the wooden frameworks like Figure 11, Figure 31 and Figure 48 is to provide many round poles in order to employ this system. A round pole can rotate if it is inserted into a hole loosely like Figure 55 (or supported by some simple towers like Figure 3 ). This device of a pole rotating in a hole can be viewed as a simplest example of "plain bearing," a shaft rotating in a hole, which is also called "sliding bearing" or "sleeve bearing." Since the pole does not have an apparent axis of rotation, it would be appropriate to call such a system "forerunner of pulley."

2) Sand: This we used as one of means in order to raise an obelisk from the bedrock up to the ground level as seen in Figure 9 and Figure 10, or to raise an obelisk from the ground to the top of mound as shown in Figure 33 and Figure 34. This way can be viewed as the "buoyancy" of sand:

Moving sand behaves like a fluid to float a stone.

In general, the aggregation of sand or any particles tends to behave like a fluid while its particles keep moving. Such knowledge about sand would be gained by ancient Egyptians through their rich experience with sand, and we believe that the "rolling" technique as in Figure 9 and Figure 10 was already used in the construction of pyramids. Note that the "buoyancy" of sand is great due to its high bulk density.

3) Rockers: We employed "rockers" to maneuver an obelisk. When placed properly under an obelisk, rockers can induce various movements of the obelisk, e.g., "rolling" (Figures 22-24), "pitching" (Figure 33) and inclination (Figure 54). "Yawing," i.e., turning the obelisk of Figure 32 horizontally, would be also possible using only the rockers $R_{1}, R_{1}^{\prime}$ under the center of mass of the obelisk. As noted before in case of the pre-obelisk, the force couple for "yawing" or "pitching" works effectively for a long object like an obelisk. A quite different usage of rocker can be seen in Figure 51 as a forerunner of simple pulley, just for the redirection of force.

Summarizing, we can conclude that the above three means cope very well with the gravity to "lighten" a heavy obelisk.

\section{Conflicts of Interest}

The author declares no conflicts of interest regarding the publication of this paper. 


\section{References}

Al-Hashemi, H. M. B., \& Al-Amoudi, O. S. B. (2018). A Review on the Angle of Repose of Granular Materials. Powder Technology, 330, 397-417. https://doi.org/10.1016/j.powtec.2018.02.003

Arnold, D. (1991). Building in Egypt. New York and Oxford: Pharaonic Stone Masonry.

Arnold, D. (2003). The Encyclopedia of Ancient Egyptian Architecture. Princeton, NJ: Princeton Univ. Press.

Blyth, E. (2006). Karnak: Evolution of a Temple. London: Routledge. https://doi.org/10.4324/9780203968376

Brier, B. (2021). Cleopatra's Needles: The Lost Obelisks of Egypt, Bloomsbury Egyptoology. London: Bloomsbury Academic.

Engelbach, R. (1922). The Aswan Obelisk: With Some Remarks on the Ancient Engineering. Cairo: Imprimerie de L'Institut Français D'Archéologie Orientale.

Engelbach, R. (1923). The Problem of the Obelisks. New York: George H. Doran Co., London: T. F. Unwin, Limited.

Favro, D. (2018). Obelisk Bones (Seleucia Sayı VIII-2018, pp. 11-26).

Gorringe, H. (1885). Egyptian Obelisks. London: John C. Nimmo.

Habachi, L. (1985). Obelisks of Egypt: Skyscrapers of the Past. Cairo: American University in Cairo Press.

Hoogeveen, T. (2018). Queen Hatshepsut's Heavy-Lift River Barge. http://historicvessels.com/queen-hatshepsuts-heavy-lift-obelisk-river-barge

Isler, M. (1976). Ancient Egyptian Methods of Raising Weights. Journal of the American Research Center in Egypt, 13, 31-42. https://doi.org/10.2307/40001116

Isler, M. (2001). Sticks, Stones, and Shadows Building the Egyptian Pyramids. Norman, OK: Univ. of Oklahoma Press.

Jansson, W. (2019). To Move an Obelisk. https://www.diva-portal.org/smash/get/diva2:1323958/FULLTEXT01.pdf

Kato, A. (2020). How They Moved and Lifted Heavy Stones to Build the Great Pyramid. Archaeological Discovery, 8, 47-62. https://doi.org/10.4236/ad.2020.81003

King, J. (1880). Cleopatra's Needle. London: Religious Tract Society.

Negus, R. (2015). The Obelisks of Egypt: The Myths of Their Construction and Erection Explored. https://grahamhancock.com/negusd1

Siwicki, C. (2020). Moving Ancient Egyptian Obelisks. https://www.gizmodo.jp/2020/12/earth-s-second-detected-minimoon.html

Soros, I. (2018). The Great Boat of Khufu: The "Black Box" to the Construction of the Pyramids.

https://www.ancient-origins.net/ancient-places-africa/great-boat-khufu-black-box-con struction-pyramids-009994

State, P. (2007). Aswan Obelisk Quarry More than Meets the Eye. Science Daily, 19 October 2007. http://www.sciencedaily.com/releases/2007/10/071016131326.htm 